RAFAEL MARQUES LINS

\title{
ESTIMADOR DE ERRO A POSTERIORI BASEADO EM RECUPERAÇÃO DO GRADIENTE PARA O MÉTODO DOS ELEMENTOS FINITOS GENERALIZADOS
}

\author{
(VERSÃO CORRIGIDA)
}

Dissertação apresentada à Escola de Engenharia de São Carlos da Universidade de São Paulo como parte dos requisitos para obtenção do título de Mestre em Engenharia de Estruturas.

Orientador: Prof. Titular Dr. Sergio Persival Baroncini Proença

São Carlos - SP 
AUTORIZO A REPRODUÇÃO E DIVULGAÇÃO TOTAL OU PARCIAL DESTE TRABALHO, POR QUALQUER MEIO CONVENCIONAL OU ELETRÔNICO, PARA FINS DE ESTUDO E PESQUISA, DESDE QUE CITADA A FONTE.

Ficha catalográfica preparada pela Seção de Tratamento da Informação do Serviço de Biblioteca - EESC/USP

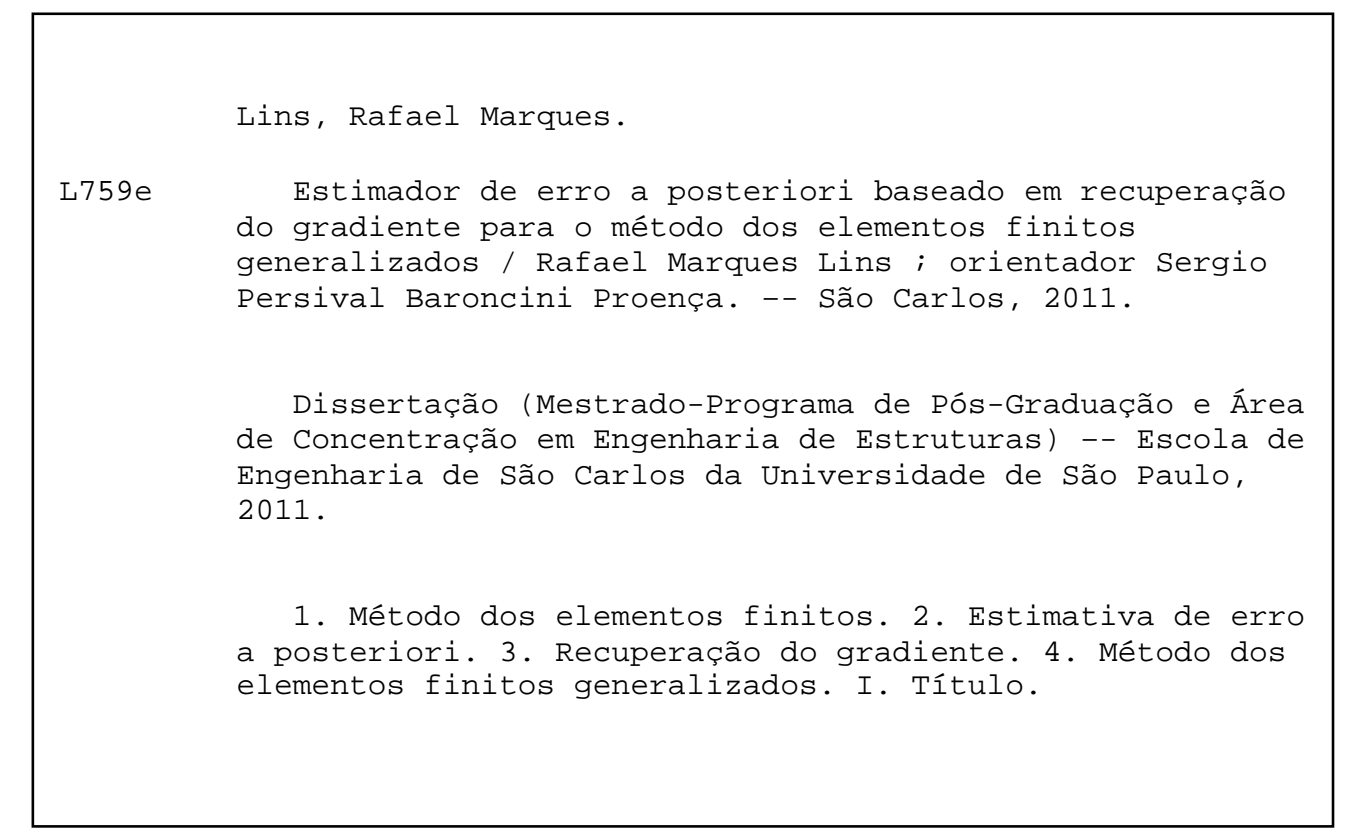


FOLHA DE JULGAMENTO

Candidato: Engenheiro RAFAEL MARQUES LINS.

Dissertação defendida e julgada em 11/05/2011 perante a Comissão Julgadora:

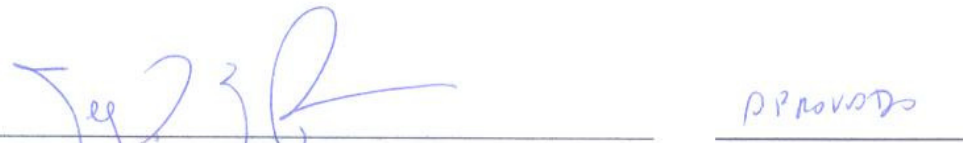

Prof. Titular SERGIO PERSIVAL BARONCINI PROENÇA - (Orientador)

(Escola de Engenharia de São Carlos/USP)

Johich him Aans APVADO

Prof. Dr. FELÍCIO BRUZZI BARROS

(Universidade Federal de Minas Gerais/UFMG)

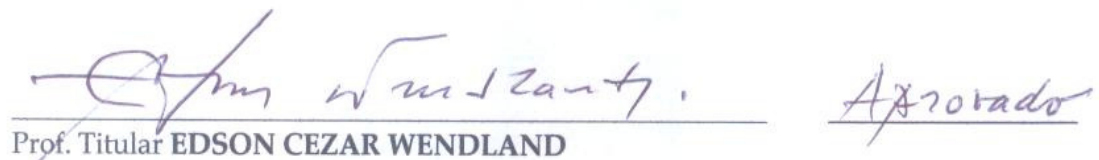

(Escola de Engenharia de São Carlos/USP)

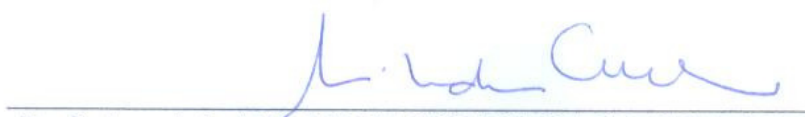

Prof ${ }^{a}$. Associada-ANA LUCIA HOMCE DE CRESCE EL DEBS

Coordenadora do Programa de Pós-Graduação em

Engenharia Civil (Engenharia de Estruturas)

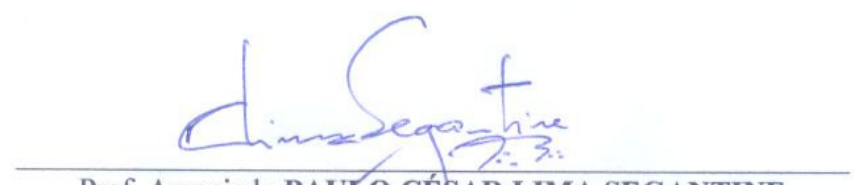

Prof. Associado PAULo CÉSAR LIMA SEGANTINE

Presidente da Comissão de Pós-Graduação 

Dedico este trabalho a minha família e a todos aqueles que torceram pela chegada deste momento. 



\section{AGRADECIMENTOS}

Ao meu orientador, Professor Sergio Persival Baroncini Proença, pela amizade concedida, por todo o conhecimento transmitido de forma impecável e acima de tudo pela imensurável paciência demonstrada ao tentar esclarecer minhas infinitas dúvidas.

Aos meus pais, José Cavalcante e Helena, e meu irmão Flávio que sempre estiveram ao meu lado me ajudando de alguma forma e foram fundamentais para a chegada desse momento.

Aos Professores Severino Pereira Cavalcanti Marques e Francisco Vieira Barros, pelo exemplo de dedicação ao ensino demonstrado ao longo da minha graduação na Universidade Federal de Alagoas que certamente servirão de espelho para mim caso venha a ingressar na carreira acadêmica.

Aos amigos André Marcon Trotta, Emerson Alexandro Bolandim, Rafael Tamanini Machado, Rafael Eclache Moreira de Camargo e Davi Fagundes Leal por compartilharem comigo boa parte dos momentos inesquecíveis que vivenciei ao longo desses últimos dois anos.

Aos companheiros de pesquisa Dorival Piedade Neto e Higor Sérgio Dantas Argôlo, pelo tempo despendido nos esclarecimentos de minhas dúvidas e, sobretudo, pela valiosa colaboração na implementação computacional deste trabalho.

Aos amigos de Maceió que demonstraram total apoio a minha decisão de sair de Alagoas para ingressar no Mestrado em São Carlos.

Aos amigos conterrâneos Saulo José de Castro Almeida e Eduardo Lucena Cavalcante de Amorim que estiveram ao meu lado desde a minha chegada com palavras de incentivo e conselhos valiosos principalmente nos dias mais complicados que passei em São Carlos.

À CAPES pelo apoio financeiro concedido.

$\mathrm{E}$ a todos aqueles que de forma direta ou indireta contribuíram com esse trabalho. 

"Deus nos faz perfeitos e não escolhe os capacitados, capacita os escolhidos. Fazer ou não fazer algo só depende de nossa vontade e perseverança." 



\section{RESUMO}

LINS, R. L. (2011). Estimador de erro a posteriori baseado em recuperação do gradiente para o método dos elementos finitos generalizados. Dissertação (Mestrado), Escola de Engenharia de São Carlos, Universidade de São Paulo, São Carlos.

O trabalho aborda a questão das estimativas a posteriori dos erros de discretização e particularmente a recuperação dos gradientes de soluções numéricas obtidas com o método dos elementos finitos (MEF) e com o método dos elementos finitos generalizados (MEFG). Inicialmente, apresenta-se, em relação ao MEF, um resumido estado da arte e conceitos fundamentais sobre este tema. Em seguida, descrevem-se os estimadores propostos para o MEF denominados Estimador Z e "Superconvergent Patch Recovery" (SPR). No âmbito do MEF propõe-se de modo original a incorporação do "Singular Value Decomposition" (SVD) ao SPR aqui mencionada como SPR Modificado. Já no contexto do MEFG, apresenta-se um novo estimador do erro intitulado EPMEFG, estendendo-se para aquele método as idéias do SPR Modificado. No EPMEFG, a função polinomial local que permite recuperar os valores nodais dos gradientes da solução tem por suporte nuvens (conjunto de elementos finitos que dividem um nó comum) e resulta da aplicação de um critério de aproximação por mínimos quadrados em relação aos pontos de superconvergência. O número destes pontos é definido a partir de uma análise em cada elemento que compõe a nuvem, considerando-se o grau da aproximação local do campo de deslocamentos enriquecidos. Exemplos numéricos elaborados com elementos lineares triangulares e quadrilaterais são resolvidos com o Estimador Z, o SPR Modificado e o EPMEFG para avaliar a eficiência de cada estimador. Essa avaliação é realizada mediante o cálculo dos índices de efetividade.

Palavras-chave: Estimativa de erro a posteriori, Recuperação do gradiente, Método dos elementos finitos generalizados. 



\section{ABSTRACT}

LINS, R. L. (2011). A posteriori error estimator based on gradient recovery for the generalized finite element method. Dissertation (M. Sc.), Escola de Engenharia de São Carlos, Universidade de São Paulo, São Carlos.

The paper addresses the issue of a posteriori estimates of discretization errors and particularly the recovery of gradients of numerical solutions obtained with the finite element method (FEM) and the generalized finite element method (GFEM). Initially, it is presented, for the MEF, a brief state of the art and fundamental concepts about this topic. Next, it is described the proposed estimators for the FEM called ZEstimator and Superconvergent Patch Recovery (SPR). It is proposed, originally, in the ambit of the FEM, the incorporation of the "Singular Value Decomposition (SVD) to SPR mentioned here as Modified SPR. On the other hand, in the context of GFEM, it is presented a new error estimator entitled EPMEFG in order to expand the ideas of Modified SPR to that method. In EPMEFG, the local polynomial function that allows to recover the nodal values of the gradients of the solution has for support clouds (set of finite elements that share a common node) and results from the applying of a criterion of least squares approximation in relation to the superconvergent points. The number of these points is defined from an analysis of each cloud's element, considering the degree of local approximation of the displacement field enriched. Numerical examples elaborated with linear triangular and quadrilateral elements are solved with the Z-Estimator, the Modified SPR and the EPMEFG to evaluate the efficiency of each estimator. This evaluation is done calculating the effectivity indexes.

Keywords: A posteriori error estimate, Gradient recovery, Generalized finite element method. 



\section{LISTA DE FIGURAS}

Figura 1.1 - Comparação entre o gradiente obtido via MEF (a) e o gradiente obtido a partir de um estimador de erro (b) 27

Figura 2.1 - Diferentes tipos de refinamento- $h$ 40

Figura 3.1 - Barra submetida ao peso próprio (Exemplo 1) 43

Figura 3.2 - Comparação entre os diferentes campos de tensões (Exemplo 1) 46

Figura 3.3 - Pontos superconvergentes para os deslocamentos (a) e para as tensões (b) em um caso unidimensional 47

Figura 3.4 - Malha de elementos quadrilaterais bilineares com nuvens que apresentam uma quantidade insuficiente de pontos ótimos 50

Figura 3.5 - Malha de elementos quadrilaterais bilineares usada para exemplificar a obtenção das tensões nodais suavizadas usando o SPR modificado 54 Figura 3.6 - Barra submetida ao peso próprio (Exemplo 2) 55

Figura 4.1 - Construção de uma função de forma do MEFG usando uma função de enriquecimento polinomial (a) e não-polinomial (b). Neste caso, $\varphi_{\alpha}$ são as funções na parte superior, $L_{\alpha i}$ são as funções no meio, e $\phi_{\alpha i}$ são as funções na parte inferior 61

Figura 4.2 - Barra submetida a um carregamento cúbico (Exemplo 3) 65

Figura 4.3 - Comparação entre os diferentes campos de tensões do elemento 1 (Exemplo 3)

Figura 4.4 - Comparação entre os diferentes campos de tensões do elemento 2 (Exemplo 3) 68

Figura 5.1 - Dados do problema resolvido com o PEAZERM2D 71

Figura 5.2 - Índices de efetividade locais do problema da Figura 5.1 calculados com a norma energia 71

Figura 5.3 - Refinamento progressivo aplicado para verificar se os estimadores estudados são assintoticamente exatos

Figura 5.4 - Índices de efetividade globais calculados com a norma energia 74

Figura 5.5 - Índices de efetividade globais calculados com a norma $L_{2}$ 74

Figura 5.6 - Viga engastada - tensão plana $-E=10^{4}, v=0,25$ 75

Figura 5.7 - Viga biapoiada - tensão plana $-E=10^{4}, v=0,25$ 75 
Figura 5.8 - Componente $\sigma_{x}$ do campo de tensões calculada com o MEFG (a), com o EPMEFG (b) e pela resposta exata (c) para a viga engastada 79 Figura 5.9 - Componente $\sigma_{y}$ do campo de tensões calculada com o MEFG (a), com o EPMEFG (b) e pela resposta exata (c) para a viga engastada 80 Figura 5.10 - Componente $\tau_{x y}$ do campo de tensões calculada com o MEFG (a), com o EPMEFG (b) e pela resposta exata (c) para a viga engastada 81 Figura 5.11 - Componente $\sigma_{x}$ do campo de tensões calculada com o MEFG (a), com o EPMEFG (b) e pela resposta exata (c) para a viga biapoiada 82 Figura 5.12 - Componente $\sigma_{y}$ do campo de tensões calculada com o MEFG (a), com o EPMEFG (b) e pela resposta exata (c) para a viga biapoiada 83 Figura 5.13 - Componente $\tau_{x y}$ do campo de tensões calculada com o MEFG (a), com o EPMEFG (b) e pela resposta exata (c) para a viga biapoiada 84 


\section{LISTA DE TABELAS}

Tabela 5.1 - Índices de efetividade globais das malhas de elementos quadrilaterais 73

Tabela 5.2 - Índices de efetividade globais das malhas de elementos triangulares 73 Tabela 5.3 - Comparação entre os índices de efetividade calculados empregando-se os valores recuperados com o EPMEFG nas situações sem enriquecimento (MEF) e com enriquecimento (MEFG) para viga engastada 76

Tabela 5.4 - Comparação entre os índices de efetividade calculados empregando-se os valores recuperados com o EPMEFG nas situações sem enriquecimento (MEF) e com enriquecimento (MEFG) para viga biapoiada 


\title{
LISTA DE ABREVIATURAS E SIGLAS
}

\author{
MEF - Método dos Elementos Finitos \\ MEFG - Método dos Elementos Finitos Generalizados \\ SVD - Singular Value Decomposition \\ SPR - Superconvergent Patch Recovery \\ MRE - Método dos Resíduos em Elementos \\ PU - Partição da Unidade
}




\section{LISTA DE SÍMBOLOS}

$\mathbf{e}_{\mathrm{u}}$ - Erro local relacionado ao campo de deslocamentos

u - Vetor de deslocamentos

$\hat{\mathbf{u}}$ - Vetor de deslocamentos aproximado

$\mathbf{e}_{\sigma}$ - Erro local relacionado ao campo de tensões

$\boldsymbol{\sigma}$ - Tensor de tensões "exato"

$\hat{\boldsymbol{\sigma}}$ - Tensor de tensões aproximado

$\mathbf{e}_{\varepsilon}$ - Erro local relacionado ao campo de deformações

$\boldsymbol{\varepsilon}$ - Tensor de deformações "exato"

$\hat{\boldsymbol{\varepsilon}}$ - Tensor de deformações aproximado

$\hat{\mathbf{e}}_{\sigma}$ - Erro local estimado relacionado ao campo de tensões

$\boldsymbol{\sigma}^{*}$ - Tensor de tensões suavizadas calculado para estimativa do erro em tensão

$\hat{\mathbf{e}}_{\varepsilon}$ - Erro local estimado relacionado ao campo de deformações

$\boldsymbol{\varepsilon}^{*}$ - Tensor de deformações suavizadas calculado para estimativa do erro em deformação

$\Omega$ - Domínio da estrutura

$\mathbf{v}$ - Vetor de deslocamentos virtuais

$\hat{\mathbf{v}}$ - Vetor de deslocamentos virtuais aproximado

$\mathbf{x}$ - Vetor com as coordenadas de um ponto

$R$ - Resíduo da solução aproximada

$\left\|\mathbf{e}_{\varepsilon}\right\|$ - Norma energia do erro do campo de deformações

$\left\|\mathbf{e}_{\boldsymbol{\sigma}}\right\|$ - Norma energia do erro do campo de tensões

$\left\|\mathbf{e}_{\varepsilon}\right\|_{L_{2}}$ - Norma $L_{2}$ do erro do campo de deformações

$\left\|\mathbf{e}_{\boldsymbol{\sigma}}\right\|_{L_{2}}$ - Norma $L_{2}$ do erro do campo de tensões

$\left\|\hat{\mathbf{e}}_{\boldsymbol{\sigma}}\right\|$ - Norma energia do erro estimado do campo de tensões

$\left\|\hat{\mathbf{e}}_{\boldsymbol{\sigma}}\right\|_{L_{2}}$ - Norma $L_{2}$ do erro estimado do campo de tensões 
$\theta_{K}$ - Índice de efetividade do elemento $K$

$\theta_{G}$ - Índice de efetividade global

$\mathbf{N}$ - Vetor linha com as funções de forma do MEF convencional

$\overline{\boldsymbol{\sigma}}^{*}$ - Vetor com os valores nodais da tensão suavizada (ou recuperada)

$E$ - Módulo de Young

$v$ - Coeficiente de Poisson

$S$ - Área da seção transversal

$q$ - Carregamento distribuído ao longo do comprimento

$\boldsymbol{\sigma}_{\mathbf{p}}^{*}$ - Polinômio que aproxima as tensões suavizadas dentro de certa nuvem

I - Matriz identidade

$\phi_{\alpha i}$ - Funções de forma do MEFG

$\varphi_{\alpha}$ - Funções de forma do MEF

$L_{\alpha i}$ - Funções enriquecedoras do MEFG

$\sigma_{x}$ - Componente normal na direção de $\mathrm{x}$ do tensor de tensões

$\sigma_{y}$ - Componente normal na direção de y do tensor de tensões

$\tau_{x y}$ - Componente cisalhante do tensor de tensões

$x_{\alpha}$ - Coordenada $\mathrm{x}$ do nó enriquecido

$y_{\alpha}$ - Coordenada y do nó enriquecido

$h$ - Dimensão característica de certa nuvem 


\section{SUMÁRIO}

LISTA DE FIGURAS__ XV

LISTA DE TABELAS___ XVii

LISTA DE ABREVIATURAS E SIGLAS__ Xix

LISTA DE SÍMBOLOS _ XXi

1. INTRODUÇÃO 25

1.1 Considerações preliminares 25

1.2 Objetivos e justificativas 27

1.3 Organização do trabalho _ 28

2. ASPECTOS GERAIS SOBRE ESTIMADORES DE ERRO __ 31

$2.1 \quad$ Estimativas de erro a posteriori__ 31

$2.2 \quad$ Normas do erro 35

2.3 Estimativa do erro e adaptabilidade _ 38

3. OS ESTIMADORES DE ERRO DE ZIENKIEWICZ E ZHU__ 41

3.1 Estimador Z 41

3.1.1 Um exemplo unidimensional ___ 43

3.2 SPR ("Superconvergent Patch Recovery") _ 46

3.2.1 Pontos de superconvergência ___ 46

3.2.2 O SPR como uma evolução para o Estimador $Z \_48$

3.3 SPR Modificado _ 51

3.3.1 Um exemplo unidimensional _ـ 55

4. A SUPERCONVERGÊNCIA APLICADA AO MEFG_ 59

4.1 Uma breve revisão sobre o MEFG 59 
4.2 Um novo estimador de erro para o MEFG

4.2.1 Um exemplo unidimensional 65

5. EXEMPLOS NUMÉRICOS 69

5.1 Descrição resumida do programa computacional desenvolvido 69

5.2 Estimadores Z e SPR Modificado 71

5.3 EPMEFG 75

6. CONSIDERAÇÕES FINAIS E CONCLUSÕES 87 REFERÊNCIAS BIBLIOGRÁFICAS 89 


\section{INTRODUÇÃO}

\subsection{Considerações preliminares}

Desde as primeiras pesquisas que vislumbraram que os modelos matemáticos de problemas em engenharia poderiam vir a ser resolvidos em forma aproximada com a ajuda de métodos numéricos, surgiu a dúvida quanto ao grau de precisão de tais soluções. Essa preocupação era e continua sendo justificável uma vez que o modelo matemático discretizado, decorrente das características associadas ao emprego de determinado método numérico, na grande maioria das vezes não consegue levar em consideração todos os detalhes que fazem parte do modelo contínuo. Por exemplo, podem ser citados, a garantia de continuidade da solução, incluindo-se diferentes ordens de derivadas, a satisfação das condições de contorno, entre outros.

Enfim, o grande desafio é saber quantificar, controlar e até mesmo minimizar o chamado erro de discretização. Dessa forma, o estudo do erro de aproximação desde os primórdios da aplicação de métodos numéricos tornou-se um tópico de pesquisa à parte.

O primeiro passo antes de entrar a fundo na discussão a respeito desse tópico é definir de maneira clara o que se entende neste trabalho por erro de aproximação. Esse conceito é aqui entendido como a diferença entre a resposta dita exata e uma solução oriunda de um procedimento aproximado. Portanto, em relação ao campo de deslocamentos, por exemplo, pode-se definir o erro como:

$$
\mathbf{e}_{\mathbf{u}}=\mathbf{u}-\hat{\mathbf{u}}
$$

onde $\hat{\mathbf{u}}$ representa uma solução obtida através de um procedimento numérico e $\mathbf{u}$ representa a solução exata. O erro pode vir a ser abordado também em outras quantidades de interesse como tensões e deformações. Nesses casos, ele passa a ser definido como: 


$$
\begin{aligned}
& e_{\sigma}=\sigma-\hat{\sigma} \\
& e_{\varepsilon}=\varepsilon-\hat{\varepsilon}
\end{aligned}
$$

É importante salientar, conforme Duarte (1991), que o erro colocado nas equações (1.1) e (1.2) diz respeito exclusivamente ao erro de discretização, não se levando em consideração os erros da integração numérica, de arredondamento e das representações da geometria e do carregamento.

Infelizmente, a determinação do erro como colocado nas equações anteriores de maneira geral não é possível, pois, na grande maioria dos problemas, não se conhece a solução exata. Dessa forma é necessário especular uma maneira de ao menos ter uma idéia da medida desse erro.

Os estimadores de erro surgiram justamente para preencher essa lacuna, substituindo as respostas exatas por soluções mais precisas que aquelas obtidas mediante algum método numérico. Essa resposta gerada, muitas vezes chamada de suavizada ou recuperada, é então usada para gerar a estimativa do erro. Logo, a equação (1.2) passa agora a ser escrita para o erro estimado como:

$$
\begin{aligned}
& \hat{\mathbf{e}}_{\sigma}=\boldsymbol{\sigma}^{*}-\hat{\boldsymbol{\sigma}} \\
& \hat{\mathbf{e}}_{\varepsilon}=\boldsymbol{\varepsilon}^{*}-\hat{\boldsymbol{\varepsilon}}
\end{aligned}
$$

onde o campo de tensões estimado, $\boldsymbol{\sigma}^{*}$, e o campo de deformações estimado, $\boldsymbol{\varepsilon}^{*}$, seriam obtidos com o estimador.

Por exemplo, uma idéia simples usada por alguns estimadores para quantificar o erro de discretização do campo de tensões obtido com o Método dos Elementos Finitos (MEF), consiste em transformar a distribuição descontínua naquele campo gerada quando este método usa de aproximações lineares para o campo de deslocamentos (Figura 1.1a), para uma contínua (Figura 1.1b) que representa uma melhor aproximação para a solução exata. É intuitivo que a distribuição contínua representa de forma mais fiel o campo de tensões, pois em domínios homogêneos esse campo deve ser contínuo ao longo de todo o domínio. 


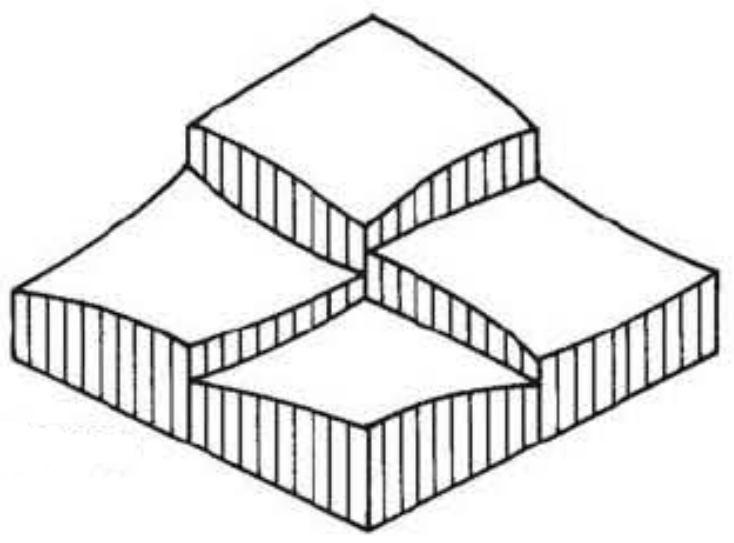

(a)

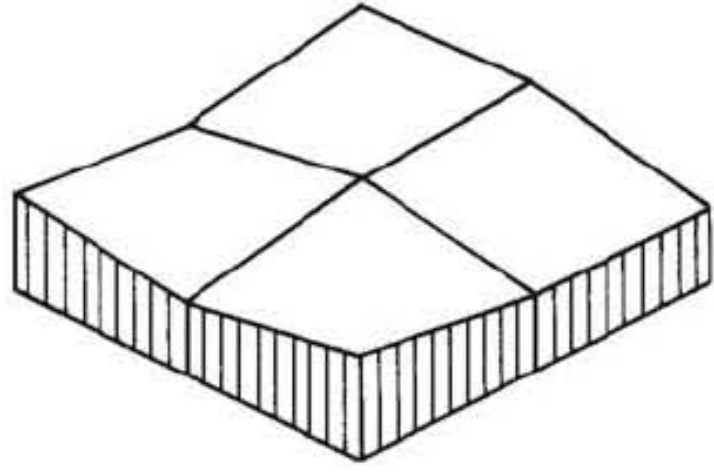

(b)

Figura 1.1 - Comparação entre o gradiente obtido via MEF (a) e o gradiente obtido a partir de um estimador de erro (b)

Adaptado: HINTON e CAMPBELL, (1974)

\subsection{Objetivos e justificativas}

Este trabalho visa em um primeiro momento fornecer um breve levantamento do atual estado da arte relacionado aos estimadores de erro a posteriori, bem como apresentar definições e conceitos matemáticos fundamentais no estudo sobre esse tema. Após essa revisão o trabalho foca suas atenções para mostrar o funcionamento, da maneira mais didática possível, do Estimador Z, proposto em Zienkiewicz e Zhu (1987), como também do "Superconvergent Patch Recovery" (SPR), proposto em Zienkiewicz e Zhu (1992a, 1992b). Apresenta-se, de modo original, uma combinação entre o SPR e a estratégia de decomposição por valores singulares, "Singular Value Decomposition" (SVD) (QUARTERONI, SACCO e SALERI; 2000), normalmente empregada para definir uma função de aproximação para um conjunto de valores dados, almejando determinar campos de tensões recuperadas. Essa nova abordagem recebe a denominação SPR Modificado. O SPR Modificado é, então, adaptado ao MEFG visando gerar estimativas do erro para esse método.

Todos os três estimadores são incorporados a uma ferramenta computacional para que exemplos numéricos, elaborados no espaço bidimensional com elementos lineares triangulares e quadrilaterais, possam vir a ser testados. Finalmente, 
comparam-se os resultados obtidos e avalia-se o grau de precisão atingido por cada estimador. A medida usada para avaliação das respostas é o índice de efetividade.

O aspecto mais relevante do presente trabalho é a apresentação de um novo estimador de erro para o Método dos Elementos Finitos Generalizados (MEFG). A importância desse novo estimador deve-se ao fato de que atualmente a literatura disponível a respeito desse assunto é ainda muito reduzida. Uma justificativa plausível para isso é o caráter relativamente recente desse método, de sorte que o estudo de estimadores de erro para o MEFG ainda é um campo de pesquisa em plena expansão. Tal afirmação já não é verdadeira para o MEF, já que é inegável que grande parte dos estimadores de erro indicados na literatura possui suas características de desempenho bastante testadas.

Os estudos propostos neste trabalho em relação aos estimadores de erro foram complementados com o desenvolvimento de uma ferramenta computacional, capaz de fornecer indicadores de erro, para uma classe de problemas de interesse, os quais podem vir a ser fundamentais para futuros processos adaptativos. Esses indicadores, construídos a partir da avaliação do erro em nível local, têm a função de apontar as regiões do domínio onde é necessário o refinamento da solução. Portanto, o programa desenvolvido fornece a matéria-prima que alimenta os algoritmos adaptativos. Os indicadores de erro evitam procedimentos onerosos que normalmente consistem em executar diversas vezes uma mesma análise para comparar as soluções até que seja encontrada uma resposta dentro de uma tolerância estabelecida de antemão.

\subsection{Organização do trabalho}

Além do capítulo de introdução, este trabalho reúne ainda mais cinco capítulos. A seguir é colocada de maneira sucinta uma descrição do conteúdo dos demais capítulos.

O capítulo 2 tem o objetivo de esclarecer os fundamentos básicos sobre o estudo dos estimadores de erro. Nesse sentido são discutidas as principais características dos estimadores de erro a posteriori. Esse mesmo capítulo traz ainda informações relacionadas às medidas de erro e a adaptabilidade. 
O capítulo 3 explica o funcionamento e apresenta as peculiaridades dos estimadores de erro desenvolvidos para o MEF abordados neste trabalho. Para tornar a abordagem mais didática, é apresentado um exemplo unidimensional para os estimadores incorporados à ferramenta computacional implementada.

O capítulo 4 é dedicado ao inédito estimador construído para o MEFG. Dessa forma, esse capítulo primeiramente expõe de modo conciso aspectos relacionados a esse método numérico para em seguida detalhar a obtenção do novo estimador.

O capítulo 5 é destinado aos exemplos numéricos que foram utilizados para avaliar os estimadores de erro. Esse capítulo expõe ainda algumas informações relacionadas ao programa computacional desenvolvido como parte integrante deste trabalho.

Finalmente, o capítulo 6 traz as considerações finais e algumas conclusões obtidas com o trabalho. Além disso, esse capítulo enumera sugestões para trabalhos futuros que possam vir a ser desenvolvidos dentro desta área. 


\section{ASPECTOS GERAIS SOBRE ESTIMADORES DE ERRO}

O objetivo deste capítulo é conceituar alguns aspectos essenciais para o estudo do erro. Inicialmente, apresenta-se um resumido estado da arte relacionado aos estimadores de erro a posteriori para o MEF. A seguir são indicadas as principais normas utilizadas para avaliar o erro. Finalmente, expõem-se, de forma abreviada, aspectos relacionados à relação entre os estimadores de erro e adaptabilidade.

\subsection{Estimativas de erro a posteriori}

O erro de discretização presente em uma solução aproximada pode ser estimado de forma a priori ou a posteriori. Estimativas de erro a priori são baseadas em informações genéricas sobre a solução analítica do problema. Essas estimativas podem fornecer informações a respeito da taxa de convergência esperada para certa estratégia adotada de refinamento da solução ("h" ou "p"), mas não são capazes de quantificar o erro de uma resposta aproximada. Entretanto, segundo Ewing (1990), é possível gerar resultados muito eficazes quando as estimativas a priori são combinadas com técnicas de extrapolação.

Por outro lado, o princípio fundamental das estimativas de erro a posteriori é usar a própria solução numérica obtida para calcular valores melhor aproximados dos campos de deslocamentos, tensões e/ou deformações. Esses valores são referenciados na bibliografia como valores recuperados. Além disso, essas estimativas podem ser empregadas para guiar o processo adaptativo, uma vez que as mesmas permitem avaliar a dimensão dos erros locais.

Atualmente existe uma diversidade de estimadores de erro a posteriori propostos na literatura. De acordo com Grätsch e Bathe (2005), as seguintes características são desejáveis para um bom estimador:

- A estimativa do erro deve ser precisa, isto é, ser bem próxima do erro verdadeiro; 
- A estimativa do erro precisa ser assintoticamente correta, ou seja, à proporção que a densidade da malha é aumentada, a estimativa do erro deve tender a zero no mesmo ritmo que o erro exato;

- Idealmente, a estimativa do erro deve produzir limites inferiores e superiores para o erro presente na solução numérica;

- A estimativa do erro não pode sobrecarregar o custo computacional total da análise;

- É necessário que o estimador do erro seja robusto com respeito a uma extensa gama de aplicações, incluindo a análise não-linear;

- Uma implementação do estimador do erro deve ser possível para guiar um processo de refinamento adaptativo para otimizar a malha empregada.

Certamente será raro descobrir um estimador de erro a posteriori que possua todas as características supracitadas, todavia o propósito aqui colocado é esclarecer que, quanto mais dessas peculiaridades o estimador dispor, mais eficiente o mesmo será.

Em Ainsworth e Oden (1997), os estimadores de erro a posteriori são classificados em dois tipos distintos: estimadores baseados em resíduo e estimadores baseados em recuperação.

Para esclarecer a diferença entre eles, considere-se o problema de valor de contorno escrito em sua forma forte para o domínio bidimensional $\Omega$ limitado pelo contorno $\partial \Omega$, no qual o objetivo é encontrar uma solução $\mathbf{u}$ tal que:

$$
-\Delta \mathbf{u}+c \mathbf{u}=\mathbf{f}(\mathbf{x})
$$

submetido as seguintes condições de contorno:

$$
\frac{\partial \mathbf{u}}{\partial \mathbf{n}}=\mathbf{g} \text { em } \Gamma_{N}
$$

e

$$
\mathbf{u}=0 \text { em } \Gamma_{D}
$$

No problema modelo governado pela equação (2.1) vale a seguinte notação: 
$\Delta$ - representa o operador laplaciano de derivadas parciais de segunda ordem.

$c$ - é uma constante não-negativa que depende do tipo do problema.

$\Gamma_{N}, \Gamma_{D}$ - são regiões complementares da superfície de contorno, isto é: $\Gamma_{N} \cup \Gamma_{D}=\partial \Omega$.

n - versor normal ao contorno $\partial \Omega$.

O mesmo problema da equação (2.1) formulado em forma fraca pode ser representado da seguinte maneira:

$$
B(\mathbf{u}, \mathbf{v})=L(\mathbf{v})
$$

onde a forma bilinear é dada por:

$$
B(\mathbf{u}, \mathbf{v})=\int_{\Omega}(\nabla \mathbf{u} \cdot \nabla \mathbf{v}+c \mathbf{u} \cdot \mathbf{v}) d \mathbf{x}
$$

e a forma linear por:

$$
L(\mathbf{v})=\int_{\Omega} \mathbf{f} \cdot \mathbf{v} d \mathbf{x}+\int_{\Gamma_{N}} \mathbf{g} \cdot \mathbf{v} d s
$$

Uma solução aproximada obtida pelo MEF para esse problema deve satisfazer a forma particular da equação (2.4):

$$
B(\hat{\mathbf{u}}, \hat{\mathbf{v}})=L(\hat{\mathbf{v}})
$$

A solução aproximada traz consigo um erro de discretização decorrente da diferença entre a solução exata, u, e a aproximada, $\hat{\mathbf{u}}$. Portanto, substituindo u em função do erro na equação (2.4), conclui-se que o resíduo da solução aproximada pode ser escrito como: 


$$
R=B(\mathbf{e}, \mathbf{v})=B(\mathbf{u}, \mathbf{v})-B(\hat{\mathbf{u}}, \mathbf{v})=L(\mathbf{v})-B(\hat{\mathbf{u}}, \mathbf{v})
$$

As estimativas de erro a posteriori baseadas em resíduo empregam 0 resultado da (2.8) para melhorar a qualidade da aproximação. Por outro lado, as estimativas de erro a posteriori baseadas em recuperação procuram melhorar a solução aproximada sem recurso direto à condição (2.8).

O trabalho de Babuška e Rheinboldt (1978) foi o primeiro a abordar a questão das estimativas baseadas em resíduo. Posteriormente outras abordagens foram introduzidas com importante destaque para o Método dos Resíduos em Elementos (MRE), Bank e Weiser (1985). Em Barros (2002), o MRE foi empregado objetivando a redução de erros de aproximação em análise não-linear para o MEFG.

Os estimadores baseados em recuperação procuram num pósprocessamento determinar novos valores do gradiente da solução, denominados por valores suavizados. A diferença entre os valores suavizados e os valores aproximados é então usada como estimador do erro. Esse estimador, apesar da sua simplicidade, fornece resultados surpreendentemente precisos. Hoje em dia existe uma variedade de procedimentos que permitem a determinação dos valores suavizados.

A técnica de obtenção de valores suavizados indicada em Zienkiewicz e Zhu (1987) é conhecida como o primeiro trabalho sobre um estimador baseado em recuperação. Depois de alguns anos, Zienkiewicz e Zhu (1992a, 1992b) apresentaram uma nova maneira de calcular os valores suavizados através de um procedimento que é denominado como "Superconvergent Patch Recovery". Ambos os procedimentos serão discutidos em detalhes no próximo capítulo deste trabalho. Podem ser citados ainda inúmeros outros trabalhos, envolvendo estimadores baseados em recuperação, tais como Babuška e Rheinboldt (1981), Kelly et al. (1983), Blacker e Belytschko (1994), Bartels e Carstensen (2000) e Carstensen e Funken (2000).

Ainsworth e Oden (1997) alertam que as estimativas a posteriori baseadas em recuperação apresentam uma deficiência, pois não levam em consideração nenhuma informação a respeito do problema original. Em contrapartida, os mesmos autores argumentam que, a depender do ponto de vista, essa característica pode ser considerada como mais um ponto positivo desse tipo de estimativa. 
Finalmente, é importante esclarecer que a escolha do tipo de estimador a posteriori empregado vai sempre depender dos interesses em pauta. Por exemplo, os estimadores baseados em resíduos são matematicamente mais completos e rigorosos, contudo, geralmente, demandam um maior esforço computacional. Em contrapartida, os estimadores baseados em recuperação, apesar de sua natureza heurística quando comparado com os estimadores baseados em resíduo, do ponto de vista prático podem ser considerados os mais eficientes.

\subsection{Normas do erro}

A definição do erro indicada no primeiro capítulo exprime um resultado local variável ao longo do domínio da solução e, para fins de emprego prático, é mais conveniente adotar uma medida dela proveniente, que estabelece um valor médio de erro para todo o domínio. Além disso, a forma local de definir o erro pode nos casos em que o erro se distribui uniformemente na maior parte do domínio estabelecer um critério muito rigoroso sobre o controle do mesmo. Devido a esse motivo, justifica-se o emprego de uma quantidade escalar que representaria o erro médio em todo domínio global.

As normas comumente empregadas para medida dos erros de discretização são a norma energia e a norma $L_{2}$. Em problemas da elasticidade bidimensional, por exemplo, a norma energia do erro aplicada aos campos de deformações e de tensões pode ser escrita, respectivamente, como:

$$
\begin{aligned}
& \left\|\mathbf{e}_{\boldsymbol{\varepsilon}}\right\|=\left[\int_{\Omega}(\boldsymbol{\varepsilon}-\hat{\boldsymbol{\varepsilon}})^{T} \mathbf{D}(\boldsymbol{\varepsilon}-\hat{\boldsymbol{\varepsilon}}) d \Omega\right]^{\frac{1}{2}} \\
& \left\|\mathbf{e}_{\boldsymbol{\sigma}}\right\|=\left[\int_{\Omega}(\boldsymbol{\sigma}-\hat{\boldsymbol{\sigma}})^{T} \mathbf{D}^{-1}(\boldsymbol{\sigma}-\hat{\boldsymbol{\sigma}}) d \Omega\right]^{\frac{1}{2}}
\end{aligned}
$$


onde $\Omega$ é o domínio no qual o problema está definido e $\mathbf{D}$ é a matriz constitutiva que relaciona tensão com deformação particularizada para estado plano considerado.

A norma $L_{2}$ é bem semelhante à norma energia, porém trata-se de uma medida mais direta, porque não envolve a matriz constitutiva. Sua aplicação aos campos de deformação e de tensão, respectivamente, fica expressa por:

$$
\begin{aligned}
& \left\|\mathbf{e}_{\boldsymbol{\varepsilon}}\right\|_{L_{2}}=\left[\int_{\Omega}(\boldsymbol{\varepsilon}-\hat{\boldsymbol{\varepsilon}})^{T}(\boldsymbol{\varepsilon}-\hat{\boldsymbol{\varepsilon}}) d \Omega\right]^{\frac{1}{2}} \\
& \left\|\mathbf{e}_{\boldsymbol{\sigma}}\right\|_{L_{2}}=\left[\int_{\Omega}(\boldsymbol{\sigma}-\hat{\boldsymbol{\sigma}})^{T}(\boldsymbol{\sigma}-\hat{\boldsymbol{\sigma}}) d \Omega\right]^{\frac{1}{2}}
\end{aligned}
$$

Quando da discretização do meio pelo MEF, ambas as normas apresentadas podem ser definidas nos domínios de cada elemento finito isolado. Nesse caso, a norma sobre todo o domínio passa a ser dada pela soma das normas de cada elemento. Por exemplo, para a norma energia do erro em tensão vale a seguinte relação:

$$
\left\|\mathbf{e}_{\boldsymbol{\sigma}}\right\|=\left(\sum_{K=1}^{m}\left\|\mathbf{e}_{\boldsymbol{\sigma}}\right\|_{K}^{2}\right)^{\frac{1}{2}}
$$

onde o índice $K$ se refere ao elemento e $m$ é a quantidade total de elementos.

Em grande parte dos problemas, valores exatos para os campos $\boldsymbol{\varepsilon}$ e $\boldsymbol{\sigma}$ não são conhecidos e, portanto, as normas descritas podem levar apenas a estimativas do erro, tanto mais precisas quanto maior o refinamento empregado para obter uma solução de referência.

Por sua vez, a obtenção de soluções aproximadas de boa qualidade, constituindo os campos $\hat{\boldsymbol{\sigma}}$ e $\hat{\boldsymbol{\varepsilon}}$, pode exigir grande refinamento da malha. $\mathrm{O}$ custoso recurso ao refinamento pode ser atenuado por melhoria dos valores aproximados mediante técnica de recuperação, a ser detalhada no que segue. Naturalmente, os valores aproximados melhorados ditos suavizados $\left(\varepsilon^{*}\right.$ e $\left.\sigma^{*}\right)$ são mais precisos que 36 
os valores resultantes da solução aproximada ( $\hat{\boldsymbol{\varepsilon}}$ e $\hat{\boldsymbol{\sigma}}$ ). Logo, uma alternativa para a construção dos estimadores de erro é empregar os valores suavizados em lugar das soluções exatas.

Seguindo esse raciocínio, as normas energia e $L_{2}$ passam a ser escritas como:

$$
\begin{aligned}
& \left\|\hat{\mathbf{e}}_{\boldsymbol{\sigma}}\right\|=\left[\int_{\Omega}\left(\boldsymbol{\sigma}^{*}-\hat{\boldsymbol{\sigma}}\right)^{T} \mathbf{D}^{-1}\left(\boldsymbol{\sigma}^{*}-\hat{\boldsymbol{\sigma}}\right) d \Omega\right]^{\frac{1}{2}} \\
& \left\|\hat{\mathbf{e}}_{\boldsymbol{\sigma}}\right\|_{L_{2}}=\left[\int_{\Omega}\left(\boldsymbol{\sigma}^{*}-\hat{\boldsymbol{\sigma}}\right)^{T}\left(\boldsymbol{\sigma}^{*}-\hat{\boldsymbol{\sigma}}\right) d \Omega\right]^{\frac{1}{2}}
\end{aligned}
$$

A qualidade dos estimadores de erro apresentados nas equações (2.14) e (2.15) pode ser avaliada por uma razão entre normas chamada índice de efetividade definida por:

$$
\theta=\frac{\left\|\hat{\mathbf{e}}_{\boldsymbol{\sigma}}\right\|}{\left\|\mathbf{e}_{\boldsymbol{\sigma}}\right\|}
$$

Quando a solução exata não for conhecida ainda assim um índice de efetividade pode ser determinado empregando-se uma solução dita de referência, comentada anteriormente, obtida a partir de um grande refinamento da discretização.

Obviamente, fica claro que quanto mais próximo da unidade for o índice de efetividade, mais confiável será o estimador. De modo mais rigoroso, o estimador do erro é dito assintoticamente exato quando o índice de efetividade tender para unidade à proporção em que se empregarem soluções mais refinadas. Em outras palavras, isso quer dizer que um bom estimador do erro deverá convergir para o erro exato na medida em que o refinamento aumenta.

Novamente considerando o emprego do MEF, o índice de efetividade pode ser definido tanto para um elemento isolado quanto para o domínio global, de sorte 
que a equação (2.16) pode ser reescrita para um elemento isolado do seguinte modo:

$$
\theta_{K}=\frac{\left\|\hat{\mathbf{e}}_{\mathbf{\sigma}}\right\|_{K}}{\left\|\mathbf{e}_{\mathbf{\sigma}}\right\|_{K}}
$$

ou ainda para o domínio global como:

$$
\theta_{G}=\frac{\left(\sum_{K=1}^{m}\left\|\hat{\mathbf{e}}_{\boldsymbol{\sigma}}\right\|_{K}^{2}\right)^{\frac{1}{2}}}{\left(\sum_{K=1}^{m}\left\|\mathbf{e}_{\boldsymbol{\sigma}}\right\|_{K}^{2}\right)^{\frac{1}{2}}}
$$

\subsection{Estimativa do erro e adaptabilidade}

Os estimadores do erro podem ser empregados em metodologias que visam melhorar a qualidade da aproximação. Os métodos chamados adaptativos modificam a malha e/ou o grau polinomial da aproximação até que um determinado nível de precisão, ou tolerância ao erro, seja alcançado. Para guiar o emprego do método adaptativo, o critério mais comum adotado é o chamado princípio da eqüidistribuição do erro. De acordo com esse princípio, a uniformidade e redução do erro medido nos elementos da malha, garantem maior qualidade da aproximação. Logo, os métodos adaptativos atuarão em regiões em que os estimadores de erro locais, também chamados de indicadores de erro, fornecerem valores destacadamente superiores aos encontrados no restante do domínio.

Existem várias maneiras de construir um método adaptativo para melhorar a qualidade da aproximação, contudo todas elas estão baseadas em uma, ou até mesmo nas duas, estratégias descritas a seguir:

a) refinamento-h: é mantida a ordem da interpolação polinomial, porém é alterada a quantidade ou o tamanho dos elementos; 
b) refinamento-p: há um aumento do grau polinomial da aproximação sem que ocorra nenhuma mudança na geometria da malha.

Zienkiewicz, Taylor e Zhu (2005) esclarecem que ocasionalmente é útil dividir as estratégias acima em subcategorias. Para o caso do refinamento-h os autores enumeram três diferentes metodologias ilustradas na Figura 2.1:

1. O refinamento é baseado na subdivisão dos elementos (Figura 2.1b). Os elementos das regiões onde o erro é acentuado são divididos em elementos menores e o contorno dos elementos originais permanece o mesmo.

2. A malha passa por uma completa regeneração (Figura 2.1c). Nessa metodologia, é gerada uma malha completamente nova, na qual os elementos originais podem diminuir ao até mesmo aumentar de tamanho.

3. Trata-se uma metodologia na qual é mantido o número total de nós conhecida como refinamento-r (Figura 2.1d). Nela ocorre um ajuste na posição dos nós para obter uma qualidade maior da resposta aproximada.

No caso do refinamento-p, os mesmos autores mencionam duas possíveis subcategorias:

1. O aumento do grau polinomial da aproximação acontece de maneira uniforme ao longo de todo o domínio.

2. O aumento do grau polinomial da aproximação acontece localmente usando refinamento hierárquico.

Ainda hoje não é possível estabelecer de antemão qual procedimento adaptativo irá apresentar melhores resultados para um determinado problema. No entanto, como regra geral, conforme Proença (2009), o refinamento-p apresenta-se mais eficiente em regiões de respostas com distribuição suave, enquanto o refinamento-h pode ser mais efetivo nas regiões de resposta com fortes gradientes localizados. Há ainda situações em que a combinação dos refinamentos $h$ e $p$, estratégia conhecida como refinamento-hp, pode proporcionar taxas de convergência bastante altas. 


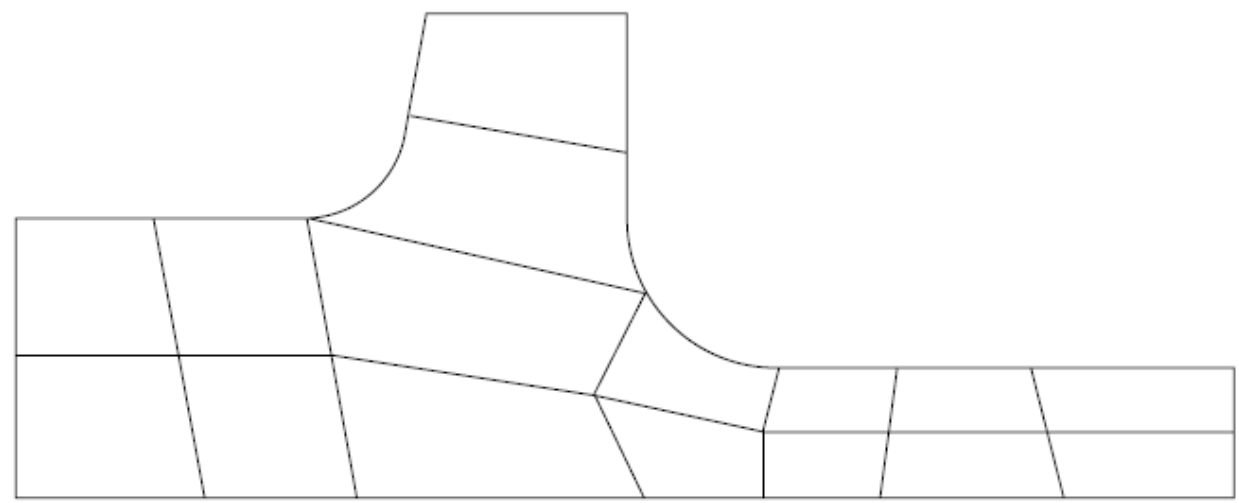

(a) Malha original

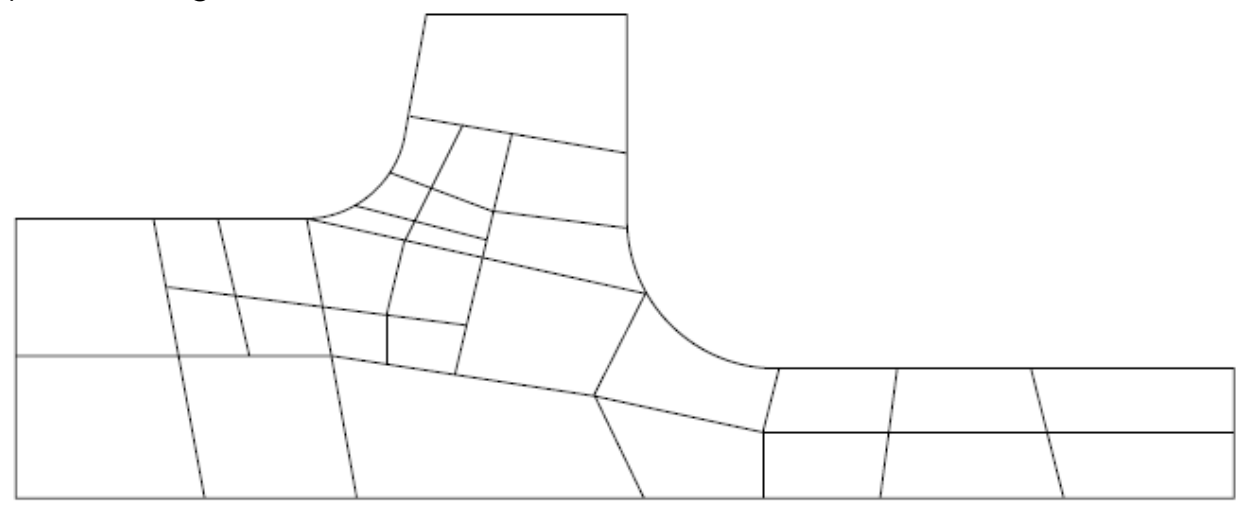

(b) Malha refinada através da subdivisão dos elementos

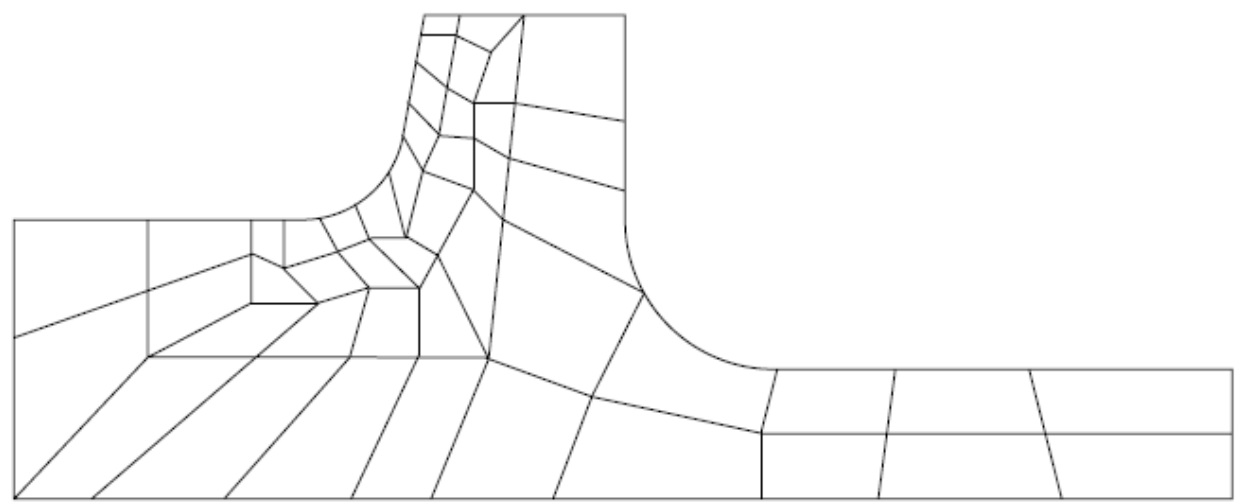

(c) Malha refinada através da completa regeneração

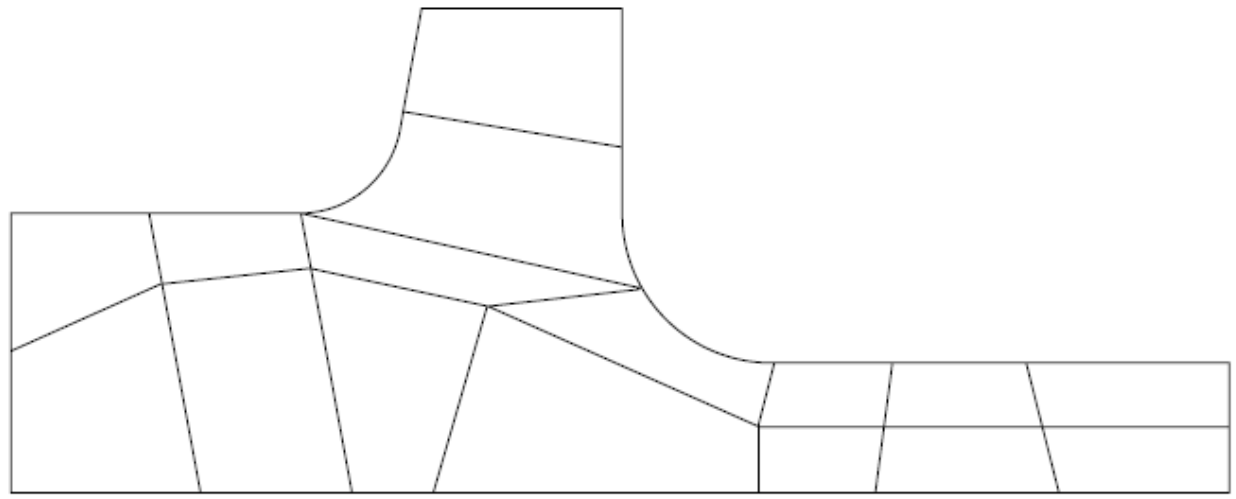

(d) Reposicionamento dos nós da malha original (refinamento-r)

Figura 2.1 - Diferentes tipos de refinamento-h Adaptado: ZIENKIEWICZ, TAYLOR e ZHU, (2005) 


\section{OS ESTIMADORES DE ERRO DE ZIENKIEWICZ E ZHU}

Este capítulo detalha dois estimadores de erro baseados em recuperação desenvolvidos por Zienkiewicz e Zhu para o MEF. O primeiro deles, chamado de Estimador Z, foi proposto em 1987. O segundo foi apresentado em 1992 como uma evolução do primeiro e é conhecido como SPR ("Superconvergent Patch Recovery"). Outro ponto discutido neste capítulo é a utilização do SVD ("Singular Value Decomposition") na determinação dos coeficientes do polinômio usado no SPR para cálculo do campo de tensões suavizadas. A incorporação do SVD ao SPR é destacada pela denominação SPR Modificado.

\subsection{Estimador Z}

Conforme já mencionado no presente trabalho, a aproximação global dos deslocamentos obtida com o MEF a partir de funções de forma lineares apresenta continuidade $\mathrm{C}^{0}$, isto é, sua derivada é descontínua entre elementos. A conseqüência disso é que ao gerar uma aproximação linear por partes o MEF leva uma distribuição de tensões com saltos na fronteira dos elementos. Zienkiewicz e Zhu (1987) então pensaram em uma forma de contornar esse problema para tornar a derivada contínua. A idéia consiste em usar a própria aproximação obtida com o MEF para calcular um novo campo de tensões de mesmo grau de continuidade da aproximação dos deslocamentos. Para isso devem ser calculados novos valores nodais de tensão e utilizadas as mesmas funções de forma dos deslocamentos para efetuar a interpolação ao longo de todo o domínio. Por conseguinte, o novo campo de tensões é escrito como:

$$
\boldsymbol{\sigma}^{*}=\mathbf{N} \overline{\boldsymbol{\sigma}}^{*}
$$

onde $\mathbf{N}$ são as mesmas funções de forma usadas na interpolação dos deslocamentos e $\overline{\boldsymbol{\sigma}}^{*}$ são novos valores nodais calculados com o auxílio da solução 
gerada com o MEF. Chama-se a atenção que a (3.1) vale componente a componente nos casos de problemas planos ou tridimensionais.

A questão crucial nesse caso é como determinar os valores nodais de tensão. Zienkiewicz e Taylor (1989) propõem que esses valores sejam obtidos a partir da minimização com respeito à $\overline{\boldsymbol{\sigma}}^{*}$ do seguinte funcional:

$$
\Pi=\int_{\Omega}\left(\boldsymbol{\sigma}^{*}-\hat{\boldsymbol{\sigma}}\right)^{T}\left(\boldsymbol{\sigma}^{*}-\hat{\boldsymbol{\sigma}}\right) d \Omega
$$

ou seja, da condição de estacionaridade e com a (3.1) segue:

$$
\begin{aligned}
& \delta \Pi=\int_{\Omega}\left(\boldsymbol{\sigma}^{*}-\hat{\boldsymbol{\sigma}}\right) \mathbf{N}^{T} d \Omega=0 \\
& \int_{\Omega}\left(\mathbf{N} \overline{\boldsymbol{\sigma}}^{*}-\hat{\boldsymbol{\sigma}}\right) \mathbf{N}^{T} d \Omega=0 \\
& \left(\int_{\Omega} \mathbf{N}^{T} \mathbf{N} d \Omega\right) \overline{\boldsymbol{\sigma}}^{*}=\left(\int_{\Omega} \mathbf{N}^{T} \hat{\boldsymbol{\sigma}}\right) d \Omega \\
& \overline{\boldsymbol{\sigma}}^{*}=\mathbf{A}^{-1}\left(\int_{\Omega} \mathbf{N}^{T} \hat{\boldsymbol{\sigma}} d \Omega\right)
\end{aligned}
$$

Na relação anterior:

$$
\mathbf{A}=\int_{\Omega} \mathbf{N}^{T} \mathbf{N} d \Omega
$$

Portanto, a determinação do campo de tensões suavizadas com o Estimador $Z$ segue o seguinte roteiro:

i. Determinação da matriz $\mathbf{A}$ a partir da equação (3.4). Essa matriz é sempre quadrada, simétrica, não-singular e positivo-definida. Sua dimensão é igual ao número total de nós;

ii. Cálculo dos novos valores nodais de tensão mediante a equação (3.3) com o auxílio da solução obtida com o MEF; 
iii. Obtenção do campo de tensões suavizadas para todo o domínio pela equação (3.1).

\subsubsection{Um exemplo unidimensional}

Para ilustrar a aplicação do roteiro acima, considere-se uma barra submetida a uma força axial distribuída, discretizada por dois elementos finitos com aproximação linear para os deslocamentos (ver Figura 3.1). Na mesma figura representa-se o campo de tensões obtido a partir da solução pelo MEF.
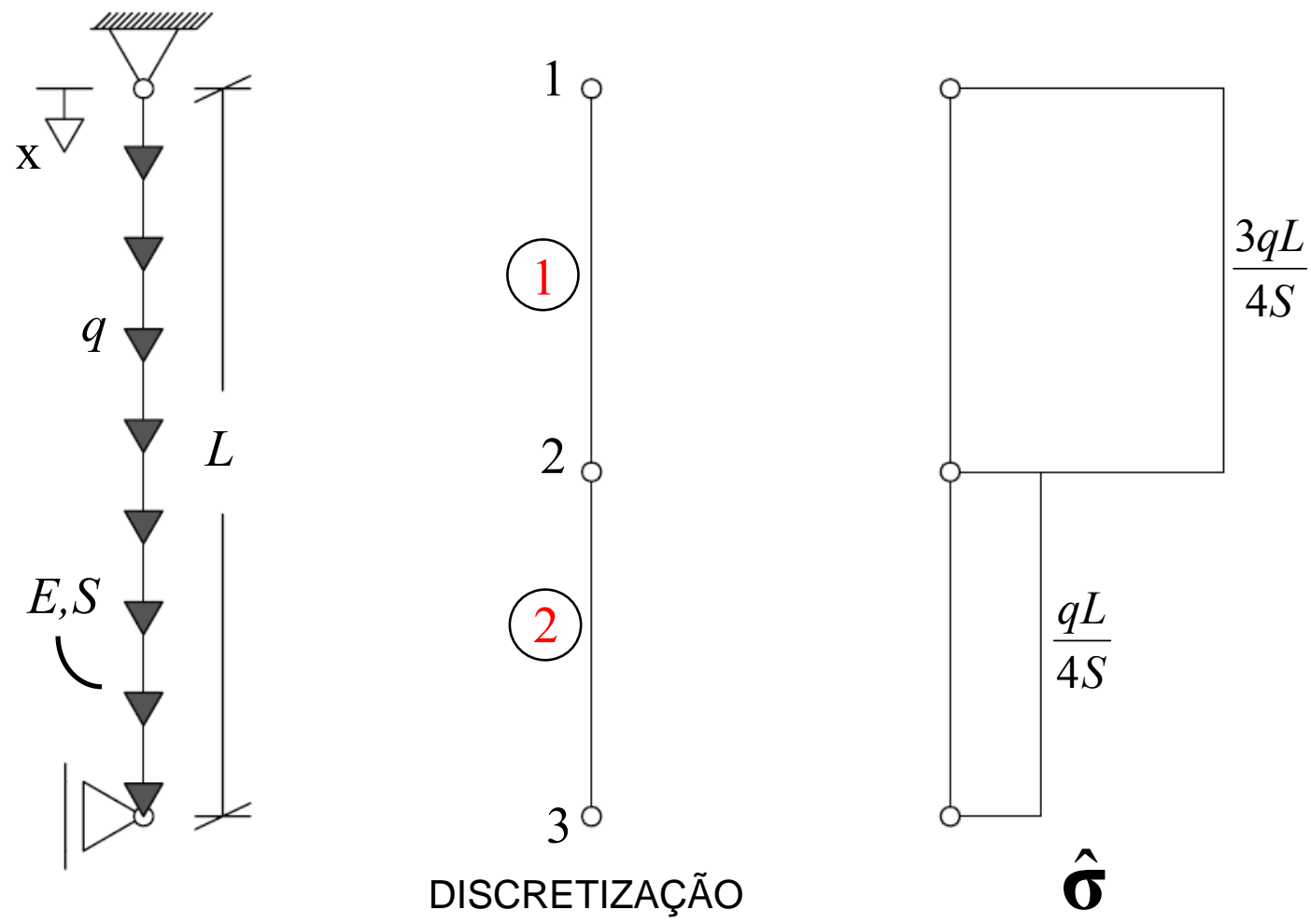

Figura 3.1 - Barra submetida ao peso próprio (Exemplo 1)

Seguindo o roteiro, o primeiro passo é determinar a matriz A. Dividindo-se o domínio de integração de modo a levar em conta a discretização com os dois elementos ilustrados na Figura 3.1 e considerando que as funções de forma são lineares em cada elemento têm-se: 


$$
\begin{aligned}
& \mathbf{A}_{1}=\int_{0}^{\frac{L}{2}}\left[\begin{array}{ccc}
\left(1-\frac{2 x}{L}\right)^{2} & \left(1-\frac{2 x}{L}\right) \frac{2 x}{L} & 0 \\
\left(1-\frac{2 x}{L}\right) \frac{2 x}{L} & \left(\frac{2 x}{L}\right)^{2} & 0 \\
0 & 0 & 0
\end{array}\right] d x=\left[\begin{array}{ccc}
\frac{L}{6} & \frac{L}{12} & 0 \\
\frac{L}{12} & \frac{L}{6} & 0 \\
0 & 0 & 0
\end{array}\right]
\end{aligned}
$$

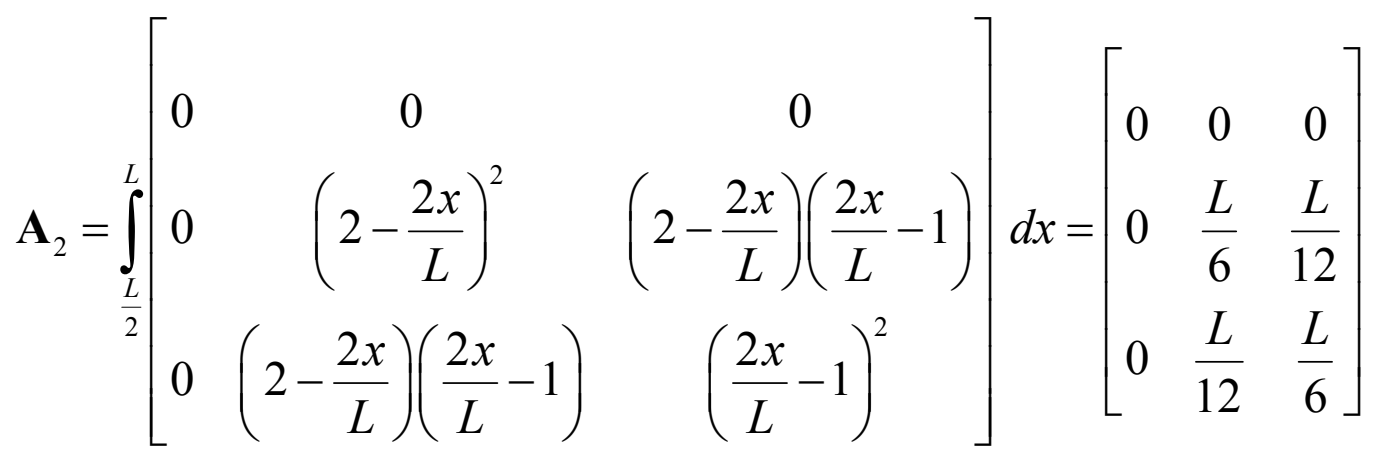

Portanto,

$$
\mathbf{A}=\mathbf{A}_{1}+\mathbf{A}_{2}=\left[\begin{array}{ccc}
\frac{L}{6} & \frac{L}{12} & 0 \\
\frac{L}{12} & \frac{L}{3} & \frac{L}{12} \\
0 & \frac{L}{12} & \frac{L}{6}
\end{array}\right]
$$

Para calcular os valores nodais de tensão é necessário primeiro calcular a integral indicada entre parênteses na equação (3.3), para depois multiplicar o resultado pela inversa de $\mathbf{A}$. Novamente, considerando-se os elementos 1 e 2, as contribuições para aquela integral são, respectivamente:

$$
\int_{0}^{\frac{L}{2}} \mathbf{N}^{T} \hat{\boldsymbol{\sigma}}_{1} d x=\int_{0}^{\frac{L}{2}}\left\{\begin{array}{c}
1-\frac{2 x}{L} \\
\frac{2 x}{L} \\
0
\end{array}\right\} \frac{3 q L}{4 S} d x=\left\{\begin{array}{c}
\frac{3 q L^{2}}{16 S} \\
\frac{3 q L^{2}}{16 S} \\
0
\end{array}\right\}
$$




$$
\int_{\frac{L}{2}}^{L} \mathbf{N}^{T} \hat{\boldsymbol{\sigma}}_{2} d x=\int_{\frac{L}{2}}^{L}\left\{\begin{array}{c}
0 \\
2-\frac{2 x}{L} \\
\frac{2 x}{L}-1
\end{array}\right\} \frac{q L}{4 S} d x=\left\{\begin{array}{c}
0 \\
\frac{q L^{2}}{16 S} \\
\frac{q L^{2}}{16 S}
\end{array}\right\}
$$

Logo,

$$
\overline{\boldsymbol{\sigma}}^{*}=\mathbf{A}^{-1}\left(\int_{0}^{\frac{L}{2}} \mathbf{N}^{T} \hat{\boldsymbol{\sigma}}_{1} d x+\int_{\frac{L}{2}}^{L} \mathbf{N}^{T} \hat{\boldsymbol{\sigma}}_{2} d x\right)=\left[\begin{array}{ccc}
\frac{7}{L} & -\frac{2}{L} & \frac{1}{L} \\
-\frac{2}{L} & \frac{4}{L} & -\frac{2}{L} \\
\frac{1}{L} & -\frac{2}{L} & \frac{7}{L}
\end{array}\right]\left\{\begin{array}{c}
\frac{3 q L^{2}}{16 S} \\
\frac{q L^{2}}{4 S} \\
\frac{q L^{2}}{16 S}
\end{array}\right\}=\left\{\begin{array}{c}
\frac{7 q L}{8 S} \\
\frac{q L}{2 S} \\
\frac{q L}{8 S}
\end{array}\right\}
$$

Finalmente, o campo de tensões suavizadas pode ser obtido com o emprego da equação (3.1). Particularizando-a para os domínios de cada elemento, resulta conseqüentemente:

$$
\begin{aligned}
& \boldsymbol{\sigma}_{1}^{*}=\left(1-\frac{2 x}{L}\right) \frac{7 q L}{8 S}+\left(\frac{2 x}{L}\right) \frac{q L}{2 S}=\frac{7 q L}{8 S}-\frac{3 q x}{4 S} \\
& \boldsymbol{\sigma}_{2}^{*}=\left(2-\frac{2 x}{L}\right) \frac{q L}{2 S}+\left(\frac{2 x}{L}-1\right) \frac{q L}{8 S}=\frac{7 q L}{8 S}-\frac{3 q x}{4 S}
\end{aligned}
$$

A Figura 3.2 ilustra uma comparação entre os três campos de tensões envolvidos nessa análise: aproximado (MEF), suavizado e exato. 


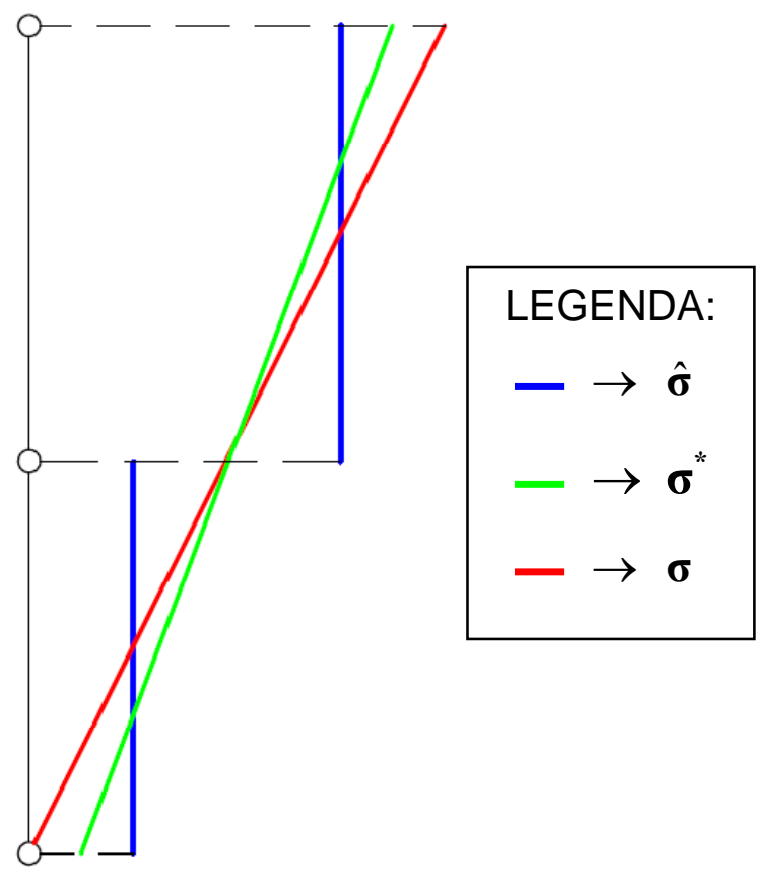

Figura 3.2 - Comparação entre os diferentes campos de tensões (Exemplo 1)

Claramente, como esperado, o campo suavizado (ou recuperado) é mais consistente com a solução exata.

\subsection{SPR ("Superconvergent Patch Recovery")}

Neste item passa-se a comentar o procedimento de recuperação do gradiente da solução denominado SPR.

\subsubsection{Pontos de superconvergência}

No MEF é axiomático que as respostas mais precisas para os deslocamentos são encontradas nos nós. Todavia, quando se trata de tensões, os valores nodais já não são precisos, ainda assim, existem pontos no interior do domínio onde o erro do campo de tensões é inferior a qualquer outro lugar. Essa característica especial passou a ser conhecida como superconvergência, observada originalmente por Barlow (1976), e tais pontos recebem o nome de pontos ótimos ou superconvergentes ou, ainda de Barlow. 
A Figura 3.3 ilustra um confronto entre a solução exata e a obtida com o MEF para uma aproximação linear por partes para os deslocamentos de um problema unidimensional. O objetivo desta figura é evidenciar a localização dos pontos superconvergentes.

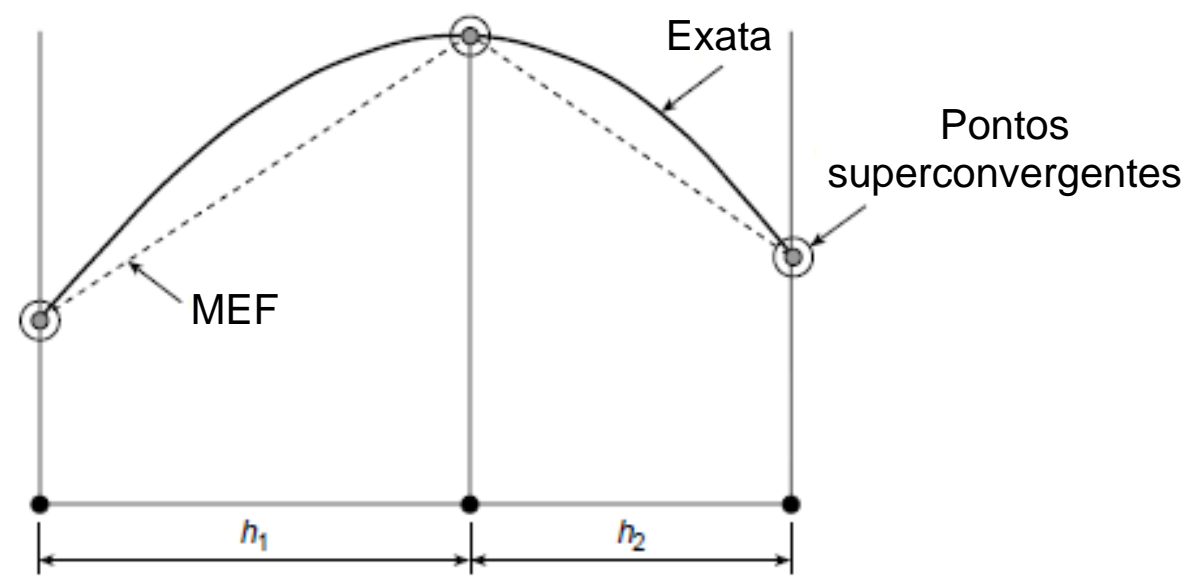

(a)

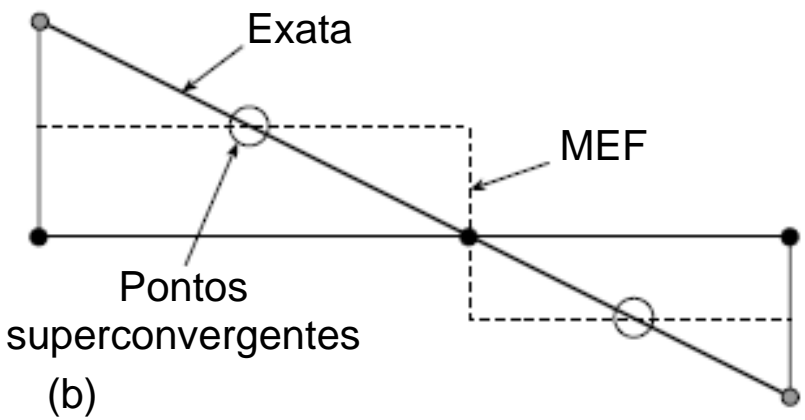

Figura 3.3 - Pontos superconvergentes para os deslocamentos (a) e para as tensões (b) em um caso unidimensional

Adaptado: ZIENKIEWICZ, TAYLOR e ZHU, (2005)

Claramente, os pontos superconvergentes para as tensões no problema da Figura 3.3 estão localizados no centro dos elementos. Essa localização coincide com os pontos de Gauss usados para integrar exatamente um polinômio linear. Portanto, como regra geral no caso unidimensional, ficou estabelecido que uma aproximação dos deslocamentos de ordem $2 n$-1 é capaz de fornecer $n$ pontos de superconvergência, cuja localização coincide com os pontos de Gauss. Por exemplo, se, ao invés de usar uma aproximação linear como no caso da Figura 3.3, tivesse sido usada uma aproximação quadrática, existiriam então dois pontos superconvergentes por elemento e não apenas um. 
Pode-se ainda justificar a característica de superconvergência nos pontos de Gauss pelo teorema de Herrmann descrito em Zienkiewicz, Taylor e Zhu (2005).

A idéia de superconvergência atrelada aos pontos de Gauss foi estendida para áreas planas de interesse para este trabalho.

\subsubsection{O SPR como uma evolução para o Estimador Z}

A partir do item anterior, pode-se concluir que se o objetivo é obter valores precisos para o campo de tensões, o mais recomendado é buscar as respostas nos pontos superconvergentes. Fundamentado nessa idéia e com o objetivo de melhorar a qualidade da aproximação para além dos pontos de superconvergência, Zienkiewicz e Zhu (1992a) propuseram o "Superconvergent Patch Recovery". Basicamente, esse estimador possui a mesma idéia do Estimador Z, ou seja, calcular o erro com o auxílio de um campo de tensões suavizadas contínuo ao longo de todo o domínio, obtido a partir da interpolação de valores nodais. No entanto, o que muda nesse caso é a maneira de calcular os valores nodais.

Essencialmente, o que o SPR faz é utilizar um ajuste por mínimos quadrados de respostas obtidas nos pontos de Barlow para gerar um polinômio que aproxima as tensões e determina os valores recuperados nos nós.

Em lugar de tratar da determinação do polinômio aproximador sobre todo o domínio, pode-se determinar polinômios que aproximam os campos de tensões dentro de "nuvens" definidas pelo conjunto de elementos que dividem um nó comum. Considerando-se, então, uma nuvem arbitrária, esse polinômio pode ser representado como:

$$
\boldsymbol{\sigma}_{\mathbf{p}}^{*}=\mathbf{P a}
$$

onde $\mathbf{P}$ reúne bases polinomiais completas ou incompletas e a é um conjunto de coeficientes a determinar pelo procedimento de ajuste por mínimos quadrados . Em Zienkiewicz e Zhu (1992a) essas bases são iguais às bases das funções de forma que aproximam os campos de deslocamentos do elemento.

Para calcular os coeficientes desconhecidos, é necessário minimizar a seguinte função em relação à a : 


$$
\begin{aligned}
F(\mathbf{a}) & =\sum_{i=1}^{n}\left(\hat{\boldsymbol{\sigma}}\left(x_{i}, y_{i}\right)-\boldsymbol{\sigma}_{\mathbf{p}}^{*}\left(x_{i}, y_{i}\right)\right)^{2} \\
& =\sum_{i=1}^{n}\left(\hat{\boldsymbol{\sigma}}\left(x_{i}, y_{i}\right)-\mathbf{P}\left(x_{i}, y_{i}\right) \mathbf{a}\right)^{2}
\end{aligned}
$$

onde $n$ é o número total de pontos ótimos, determinado pela soma do número de pontos superconvergentes de cada elemento que compõe a nuvem e $\left(x_{i}, y_{i}\right)$ são as coordenadas desses pontos.

Com a minimização obtém-se o seguinte sistema:

$$
\mathbf{a}=\mathbf{A}^{-1} \mathbf{b}
$$

sendo,

$$
\begin{aligned}
\mathbf{A} & =\sum_{i=1}^{n} \mathbf{P}^{T}\left(x_{i}, y_{i}\right) \mathbf{P}\left(x_{i}, y_{i}\right) \\
\mathbf{b} & =\sum_{i=1}^{n} \mathbf{P}^{T}\left(x_{i}, y_{i}\right) \hat{\boldsymbol{\sigma}}\left(x_{i}, y_{i}\right)
\end{aligned}
$$

Uma vez determinados os coeficientes do polinômio, basta substituir as coordenadas do nó central da nuvem para calcular $\overline{\boldsymbol{\sigma}}^{*}$. Com os valores nodais emprega-se a equação (3.1) para obter uma distribuição ao longo de todo o conjunto de elementos. Em Zienkiewicz, Taylor e Zhu (2005), é mostrado um exemplo da obtenção dos coeficientes do polinômio para um problema plano.

Um fato pertinente observado por Zienkiewicz e Zhu (1992a) é que a metodologia descrita acima funciona bem mesmo quando são utilizados mais pontos superconvergentes do que o necessário. É o caso de utilizar 2 × 2 pontos de Gauss para elementos quadrilaterais bilineares.

É importante salientar que em alguns casos (como fronteiras entre materiais distintos ou nuvens com elementos de ordem superior) pode acontecer de um nó pertencer a mais de uma nuvem. Em casos como esse Zienkiewicz e Zhu (1992a) recomendam que seja utilizado um valor médio. Pode surgir outra situação 
complicada em nuvens onde a quantidade de pontos ótimos é insuficiente para preservar o mesmo grau do polinômio de aproximação. Nessa situação, os mesmos autores recomendam que se utilize o polinômio aproximador obtido na nuvem mais próxima, ou vizinha, para determinar os valores nodais. Por exemplo, na malha indicada na Figura 3.4, são necessários no mínimo quatro pontos ótimos por nuvem e isso só ocorre para a nuvem do nó indicado pela cor azul. Conseqüentemente, todos os outros nós terão suas tensões obtidas com o polinômio dessa nuvem.

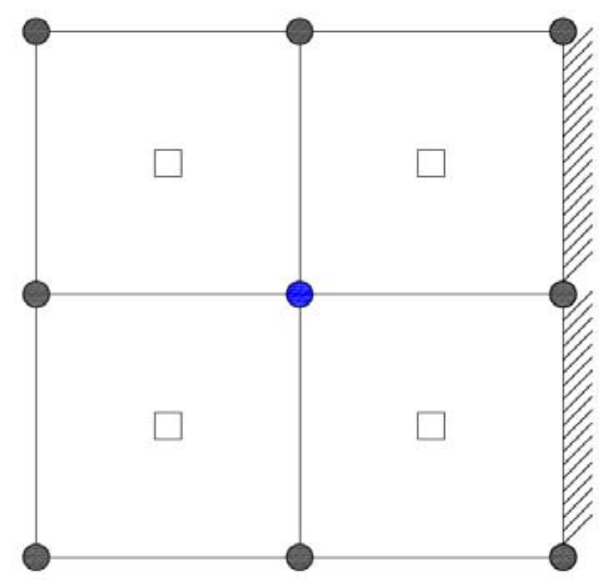

LEGENDA:

$\square$ : pontos ótimos

: nó centro de nuvem com quantidade suficiente de pontos ótimos

: nó centro de nuvem com quantidade insuficiente de pontos ótimos

Figura 3.4 - Malha de elementos quadrilaterais bilineares com nuvens que apresentam uma quantidade insuficiente de pontos ótimos

O SPR fornece uma estimativa do erro confiável até mesmo para malhas irregulares construídas arbitrariamente, conforme demonstrado em Zienkiewicz e Zhu (1992b). Entretanto, este procedimento também apresenta algumas limitações. Segundo Grätsch e Bathe (2005), sua aplicação não é eficiente na presença de descontinuidades de material. Além disso, os autores complementam que, devido ao pressuposto implícito de que oscilações indicam erros e que tensões suavizadas são mais precisas, pode acontecer de o SPR falhar quando a própria solução aproximada já é suave. Este ponto fraco do SPR é demonstrado através de um exemplo. 


\subsection{SPR Modificado}

Esse estimador é bem similar ao SPR, entretanto o que muda é a forma de calcular o polinômio que aproxima as tensões dentro das nuvens. Nesse caso, permanece a mesma idéia de que o polinômio a ser obtido apresenta a mesma ordem da aproximação dos deslocamentos, todavia seus coeficientes são determinados com o auxílio de um procedimento de decomposição da matriz do sistema denominado "Singular Value Decomposition". A seguir é colocada uma explicação, baseada em Proença (2010), sobre o SVD.

Antes de mais nada é necessário relembrar o cenário do problema. Limitandose a análise a um domínio plano, o que se conhece são valores de tensão $\hat{\boldsymbol{\sigma}}_{i}$ em um número $N_{p}$ de pontos superconvergentes dentro de uma nuvem. O objetivo então é identificar, com o auxílio dos valores de tensão $\hat{\boldsymbol{\sigma}}_{i}$ um polinômio langrangiano $\boldsymbol{\sigma}_{\mathbf{p}}^{*}(x, y)$ definido sobre toda a nuvem e que constitua uma aproximação suave em relação a todos os pontos superconvergentes.

Esse polinômio pode ser expresso na forma de uma combinação linear de uma base de funções capazes de fornecer uma aproximação com o grau de regularidade almejado, ou seja:

$$
\boldsymbol{\sigma}_{\mathbf{p}}^{*}(x, y)=\sum_{j=1}^{n} \alpha_{j} \hat{N}_{j}(x, y)
$$

onde $\hat{N}_{j}(x, y)$ são os termos polinomiais apropriados da base, $\alpha_{j}$ são os coeficientes do polinômio e o índice $n$ se refere à dimensão escolhida da base de aproximação.

O cálculo dos $\alpha_{j}$ se baseia, então, na imposição preliminar da igualdade entre os valores fornecidos pelo polinômio aproximado e os valores superconvergentes $\hat{\boldsymbol{\sigma}}_{i}$. Isso origina o seguinte sistema:

$$
\mathbf{A} \boldsymbol{\alpha}=\hat{\boldsymbol{\sigma}}
$$


onde:

$$
\mathbf{A}=\left[\begin{array}{cccc}
\hat{N}_{1}\left(x_{1}, y_{1}\right) & \hat{N}_{2}\left(x_{1}, y_{1}\right) & \cdots & \hat{N}_{n}\left(x_{1}, y_{1}\right) \\
\hat{N}_{1}\left(x_{2}, y_{2}\right) & \hat{N}_{2}\left(x_{2}, y_{2}\right) & \cdots & \hat{N}_{n}\left(x_{2}, y_{2}\right) \\
\vdots & \vdots & \ddots & \vdots \\
\hat{N}_{1}\left(x_{N_{p}}, y_{N_{p}}\right) & \hat{N}_{2}\left(x_{N_{p}}, y_{N_{p}}\right) & \cdots & \hat{N}_{n}\left(x_{N_{p}}, y_{N_{p}}\right)
\end{array}\right]
$$

e

$$
\hat{\boldsymbol{\sigma}}=\left\{\begin{array}{c}
\hat{\sigma}_{1} \\
\hat{\sigma}_{2} \\
\vdots \\
\hat{\sigma}_{N_{p}}
\end{array}\right\}
$$

Para garantir a determinação dos coeficientes $\alpha_{j}$ é imprescindível que o número de pontos superconvergentes seja maior ou igual ao número de coeficientes. Se a matriz do sistema for quadrada, o polinômio resultante realiza uma interpolação dos valores prescritos nos pontos de superconvergência. Entretanto, pode acontecer de o sistema indicado na equação (3.10) apresentar mais equações do que incógnitas. Para isso basta que o número de pontos superconvergentes seja superior ao número de coeficientes do polinômio. Nesse caso, tem-se um problema de aproximação e o objetivo passa a ser o de encontrar uma aproximação que represente $o$ melhor ajuste em relação aos valores nos pontos de superconvergência. A idéia de aplicar o SVD decorre de sua utilidade para realizar esse ajuste.

O SVD pode ser entendido como uma técnica de decomposição da matriz do sistema baseada em problemas de autovalor. Segundo o SVD, a matriz do sistema pode ser reescrita na seguinte forma:

$$
\mathbf{A}=\mathbf{U} \boldsymbol{\Sigma} \mathbf{V}^{T}
$$

onde $\mathbf{U}$ e $\mathbf{V}^{T}$ são matrizes construídas a partir de bases vetoriais tais que:

$$
\mathbf{U}^{T} \mathbf{U}=\mathbf{I} ; \mathbf{V} \mathbf{V}^{T}=\mathbf{I}
$$


A matriz $\boldsymbol{\Sigma}$ comumente é retangular, reunindo como componentes da diagonal principal (índices de linha e coluna iguais) as raízes quadradas de autovalores da matriz $\mathbf{A A}^{T}$ ordenados em forma decrescente. Os outros componentes da matriz são nulos.

A base vetorial que acaba gerando a matriz $\mathbf{U}$ é formada pelos auto-versores da matriz $\mathbf{A} \mathbf{A}^{T}$ dispostos segundo suas colunas. A base vetorial que gera a matriz é $\mathbf{V}$ formada por auto-versores da matriz $\mathbf{A}^{T} \mathbf{A}$ dispostos segundo suas linhas.

Com a decomposição da matriz A , é possível empregar a sua pseudoinversa, representada por $\mathbf{A}^{+}$, para resolver o sistema. A matriz pseudo-inversa é definida por:

$$
\mathbf{A}^{+}=\mathbf{V} \boldsymbol{\Sigma}^{+} \mathbf{U}^{T}
$$

Na relação anterior $\boldsymbol{\Sigma}^{+}$é formada, em termos gerais, pela transposta de $\boldsymbol{\Sigma}$, contudo tomando-se o inverso dos valores dos seus termos não-nulos.

Uma vez determinada a aproximação pelo SVD, a etapa seguinte objetivando a determinação das tensões suavizadas é substituir as coordenadas do nó central da nuvem no polinômio calculado para determinar $\overline{\boldsymbol{\sigma}}^{*}$. Se por acaso, analogamente ao que foi comentado anteriormente e ilustrado na Figura 3.4, certa nuvem não apresentar o número suficiente de pontos ótimos para preservar o mesmo grau do polinômio de aproximação, para determinar o valor nodal adota-se o polinômio aproximador obtido na nuvem mais próxima, ou vizinha. Em seguida, aplica-se a equação (3.1) para obter o campo de tensões para todo o domínio.

Assim sendo, a obtenção do campo de tensões suavizadas com o SPR Modificado segue o seguinte roteiro:

i. Classificação dos nós em internos e de contorno. Definida uma dimensão para a base de aproximação na (3.9), o nó é interno quando a nuvem da qual for centro apresentar pontos superconvergentes suficientes para o cálculo de $\boldsymbol{\sigma}_{\mathbf{p}}^{*}(x, y)$. Quando isso não acontece o nó é classificado como de contorno (normalmente, nós centrais de nuvens definidas no contorno do domínio enquadram-se nesta categoria); 
ii. Cálculo de $\boldsymbol{\sigma}_{\mathbf{p}}^{*}(x, y)$, com a ajuda do SVD, nas nuvens cujo nó central foi classificado como interno;

iii. Substituição das coordenadas dos nós internos em $\boldsymbol{\sigma}_{\mathbf{p}}^{*}(x, y)$ para determinação das tensões nodais suavizadas.

iv. Para cada nó de contorno identificar nó interno central de nuvem mais próximo. Esse procedimento visa descobrir qual seria o polinômio $\boldsymbol{\sigma}_{\mathbf{p}}^{*}(x, y)$, a ser usado para determinar as tensões suavizadas desse nó de contorno.

v. Obtenção das tensões suavizadas nos nós de contorno. Para isso utiliza-se o polinômio $\boldsymbol{\sigma}_{\mathbf{p}}^{*}(x, y)$ definido na nuvem cujo nó central foi identificado como o mais próximo. Por exemplo, na Figura 3.5, as tensões suavizadas dos nós 1, 2, 5, 9 e 10 seriam calculadas com o polinômio obtido na nuvem do nó 6, enquanto as tensões suavizadas dos nós 3, 4, 8, 11 e 12 seriam calculadas com o polinômio obtido na nuvem do nó 7.

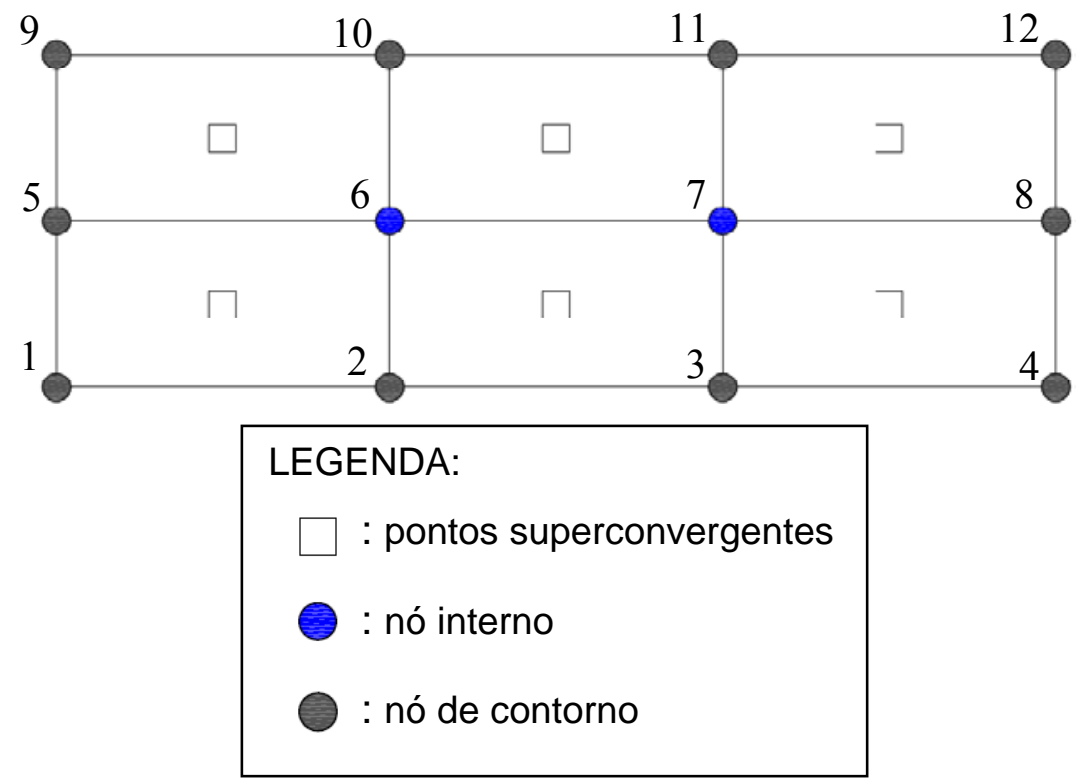

Figura 3.5 - Malha de elementos quadrilaterais bilineares usada para exemplificar a obtenção das tensões nodais suavizadas usando o SPR modificado

vi. Determinação do campo de tensões suavizadas para todo o domínio com o auxílio da equação (3.1). 


\subsubsection{Um exemplo unidimensional}
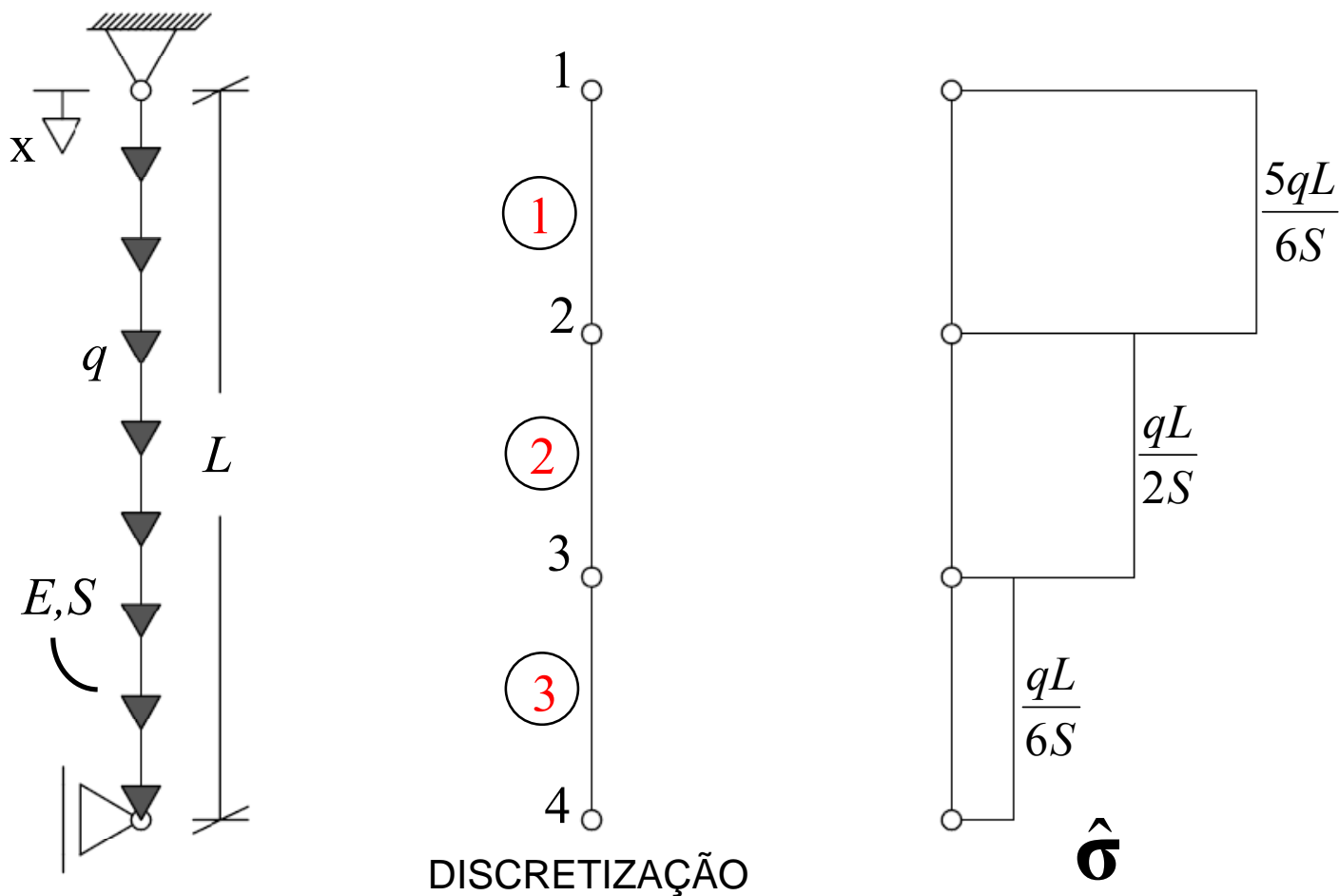

Figura 3.6 - Barra submetida ao peso próprio (Exemplo 2)

Nesse caso visto que a aproximação dos deslocamentos é linear, conclui-se que cada elemento fornecerá um ponto de superconvergência localizado em seu centro. Além disso, devido também a ordem da aproximação dos deslocamentos é possível dizer que o campo final de tensões suavizadas recuperadas será uma reta.

De acordo com o que foi colocado no roteiro, o primeiro passo na resolução de um problema desse tipo é a classificação dos nós. Nesse exemplo, o nó será classificado como interno quando a nuvem da qual for centro possuir dois pontos de superconvergência, uma vez que o campo de tensões suavizadas é definido por uma reta. Logo, os nós 2 e 3 são internos enquanto os nós 1 e 4 são de contorno.

A etapa seguinte é determinar $\boldsymbol{\sigma}_{\mathbf{p}}^{*}(x)$ nas nuvens cujo nó central é interno. Por conseguinte, para as nuvens 2 e 3 é razoável escrever que:

$$
\begin{aligned}
& \boldsymbol{\sigma}_{\mathbf{p}, 2}^{*}(x)=\alpha_{1}+\alpha_{2} x \\
& \boldsymbol{\sigma}_{\mathbf{p}, 3}^{*}(x)=\alpha_{3}+\alpha_{4} x
\end{aligned}
$$


Para calcular os coeficientes, é preciso construir um sistema para cada nuvem com a mesma estrutura daquele colocado na equação (3.10), impondo a igualdade entre os valores fornecidos pelo polinômio aproximado e os valores obtidos nos pontos superconvergentes. Portanto:

$$
\begin{aligned}
& {\left[\begin{array}{ll}
1 & \frac{L}{6} \\
1 & \frac{L}{2}
\end{array}\right]\left\{\begin{array}{l}
\alpha_{1} \\
\alpha_{2}
\end{array}\right\}=\left\{\begin{array}{c}
\frac{5 q L}{6 S} \\
\frac{q L}{2 S}
\end{array}\right\}} \\
& {\left[\begin{array}{cc}
1 & \frac{L}{2} \\
1 & \frac{5 L}{6}
\end{array}\right]\left\{\begin{array}{l}
\alpha_{3} \\
\alpha_{4}
\end{array}\right\}=\left\{\begin{array}{l}
\frac{q L}{2 S} \\
\frac{q L}{6 S}
\end{array}\right\}}
\end{aligned}
$$

Com o auxílio do SVD, obtêm-se os valores dos coeficientes, e os polinômios que aproximam as tensões suavizadas dentro das nuvens podem ser reescritos como:

$$
\begin{aligned}
& \boldsymbol{\sigma}_{\mathbf{p}, 2}^{*}(x)=\frac{q L}{S}-\frac{q}{S} x \\
& \boldsymbol{\sigma}_{\mathbf{p}, 3}^{*}(x)=\frac{q L}{S}-\frac{q}{S} x
\end{aligned}
$$

Substituindo as coordenadas dos nós internos, vem que:

$$
\begin{aligned}
& \overline{\boldsymbol{\sigma}}_{2}^{*}=\boldsymbol{\sigma}_{\mathbf{p}, 2}^{*}\left(\frac{L}{3}\right)=\frac{q L}{S}-\frac{q}{S} \cdot \frac{L}{3}=\frac{2 q L}{3 S} \\
& \overline{\boldsymbol{\sigma}}_{3}^{*}=\boldsymbol{\sigma}_{\mathbf{p}, 3}^{*}\left(\frac{2 L}{3}\right)=\frac{q L}{S}-\frac{q}{S} \cdot \frac{2 L}{3}=\frac{q L}{3}
\end{aligned}
$$

Claramente através da Figura 3.6, é possível perceber que o nó interno mais próximo do nó 1 é o nó 2 e que o mais perto do nó 4 é o nó 3. Desse modo, os valores da tensão suavizada nos nós de contorno são: 


$$
\begin{aligned}
& \overline{\boldsymbol{\sigma}}_{1}^{*}=\boldsymbol{\sigma}_{\mathbf{p}, 2}^{*}(0)=\frac{q L}{S}-\frac{q}{S} \cdot 0=\frac{q L}{S} \\
& \overline{\boldsymbol{\sigma}}_{4}^{*}=\boldsymbol{\sigma}_{\mathbf{p}, 3}^{*}(L)=\frac{q L}{S}-\frac{q}{S} \cdot L=0
\end{aligned}
$$

Com a obtenção das tensões nodais suavizadas emprega-se a equação (3.1) para determinar $\boldsymbol{\sigma}^{*}$. Logo,

Elemento 1: $\boldsymbol{\sigma}_{1}^{*}=\left(1-\frac{3 x}{L}\right) \cdot \frac{q L}{S}+\left(\frac{3 x}{L}\right) \cdot \frac{2 q L}{3 S}=\frac{q L}{S}-\frac{q}{S} x$

Elemento 2: $\boldsymbol{\sigma}_{2}^{*}=\left(2-\frac{3 x}{L}\right) \cdot \frac{2 q L}{3 S}+\left(\frac{3 x}{L}-1\right) \cdot \frac{q L}{3 S}=\frac{q L}{S}-\frac{q}{S} x$

Elemento 3: $\boldsymbol{\sigma}_{3}^{*}=\left(3-\frac{3 x}{L}\right) \cdot \frac{q L}{3 S}+\left(\frac{3 x}{L}-2\right) \cdot 0=\frac{q L}{S}-\frac{q}{S} x$

Assim sendo, conclui-se nesse exemplo que o erro estimado é idêntico ao erro exato, uma vez que as tensões exatas coincidem com as tensões suavizadas. 


\section{A SUPERCONVERGÊNCIA APLICADA AO MEFG}

O intuito deste capítulo é mostrar inicialmente uma sucinta revisão sobre o MEFG para em seguida apresentar um novo estimador de erro desenvolvido para esse método numérico. Esse estimador é semelhante ao SPR Modificado e também utiliza os resultados obtidos nos pontos superconvergentes para gerar um campo de tensões suavizadas. No entanto, há algumas diferenças em relação ao SPR Modificado que acontecem devido às peculiaridades do MEFG. Essas diferenças são enfatizadas e justificadas a seguir.

\subsection{Uma breve revisão sobre o MEFG}

De acordo com Duarte, Babuška e Oden (2000) o MEFG resultou de contribuições propostas de forma independente por:

- Babuška, Caloz e Osborn (1994) inicialmente sob a alcunha de Método dos Elementos Finitos Especiais, e Melenk e Babuška (1996) e Babuška e Melenk (1997) como Método dos Elementos Finitos Partição da Unidade;

- Duarte e Oden (1995, 1996b, 1996a) e Duarte (1996) como Método das Nuvens Hp, e Oden, Duarte e Zienkiewicz (1998) como Método dos Elementos Finitos baseado em Nuvens Hp. O MEFG seria então, um método híbrido entre o Método das Nuvens Hp e o MEF.

No MEFG a utilização de uma malha de elementos e o emprego de funções de forma típicas do MEF como partição da unidade (PU) advêm dos trabalhos de Babuška e colegas. Por outro lado, o conceito de nuvem e a idéia de enriquecimento da função de forma adicionando-se novos parâmetros nodais àqueles inicialmente existentes decorrem dos trabalhos de Duarte e Oden.

Devido à associação destacada no parágrafo anterior o MEFG consegue reunir os principais pontos positivos do MEF e propriedades muito favoráveis típicas dos métodos sem malha. 
Torres (2003) destaca que as características positivas provenientes do MEF são: a simplicidade na geração da PU devido ao uso da interpolação lagrangiana, o fato da malha de elementos já funcionar como domínio para a integração numérica, o fato de ser um método robusto para o qual já existem inúmeros códigos que podem ser adaptados ao MEFG e a facilidade na imposição das condições de contorno essenciais.

O mesmo autor citado no parágrafo anterior argumenta que as propriedades favoráveis típicas dos métodos sem malha presentes no MEFG são: a possibilidade de modelar a ocorrência de trincas ou regiões de maior concentração de tensões através da introdução de funções especiais, a maior facilidade de aplicar o refinamento-p e a possibilidade de enriquecer a aproximação apenas numa região do domínio, sem comprometer, como no MEF, a conformidade entre elementos.

Em conseqüência de suas potencialidades o MEFG vem sendo empregado em uma vasta quantidade de problemas de engenharia. No âmbito dos estudos desenvolvidos na EESC/USP algumas dessas aplicações podem ser encontradas nos trabalhos de Barros (2002), Torres (2003), Mangini (2006), Alves (2010) e Argôlo (2010).

Basicamente, o que diferencia MEF e o MEFG é a definição das funções de forma. No MEFG as funções de forma, $\phi_{\alpha i}$, tem por domínio uma nuvem, $\alpha$, definida pelo conjunto de elementos que têm um nó como vértice comum. Dentro de cada nuvem a função de forma resulta do produto entre as funções PU do MEF, $\varphi_{\alpha}$, e as chamadas funções de enriquecimento, $L_{\alpha i}$, ou seja:

$$
\phi_{\alpha i}=\varphi_{\alpha} L_{\alpha i}
$$

Na equação (4.1) vale a seguinte notação:

$\varphi_{\alpha}$ - composta pelas funções de forma do MEF tomadas em cada elemento que compõem a nuvem $\alpha$ e atreladas ao nó comum.

$L_{\alpha i}$ - funções enriquecedoras adotadas com $i=1, \ldots, n l$, onde $n l$ se refere ao número total dessas funções.

As funções de enriquecimento têm por objetivo aprimorar a qualidade da aproximação local e podem apresentar características especiais, ou mesmo ser 
definidas a partir de um conhecimento prévio da solução, de modo que não se resumem somente a bases polinomiais.

A Figura 4.1 mostra a construção de uma função de forma do MEFG.

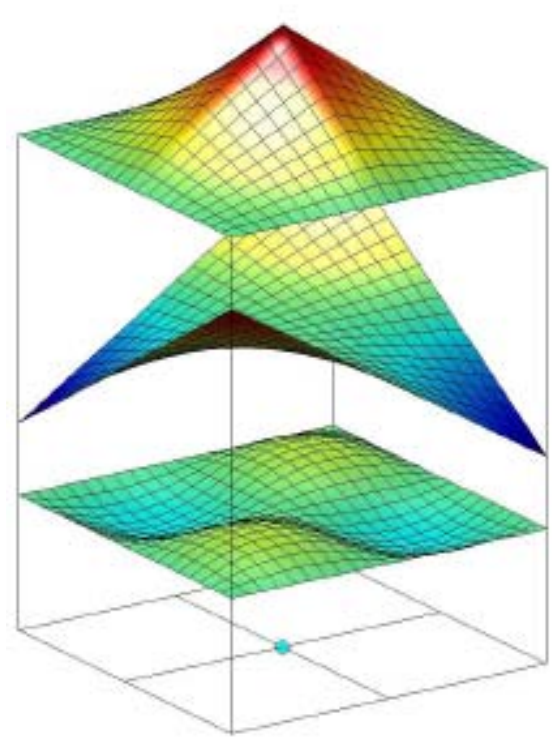

(a)

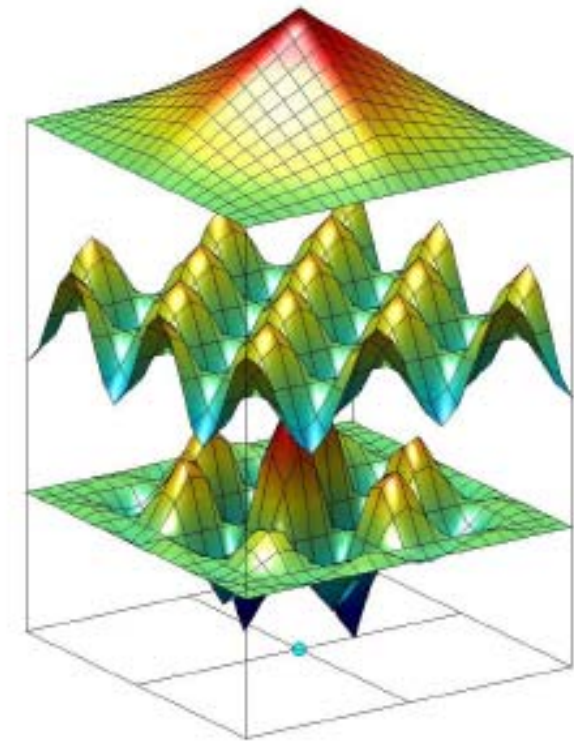

(b)

Figura 4.1 - Construção de uma função de forma do MEFG usando uma função de enriquecimento polinomial (a) e não-polinomial (b). Neste caso, $\varphi_{\alpha}$ são as funções na parte superior, $L_{\alpha i}$ são as funções no meio, e $\phi_{\alpha i}$ são as funções na parte inferior

Adaptado: KIM, DUARTE e PROENÇA, (2009)

Pode-se exemplificar para o caso bidimensional a representação formal das funções de aproximação globais do MEFG para cada uma das componentes do campo de deslocamentos aproximado, considerando-se todo o conjunto de nuvens definidas por certa discretização adotada:

$$
\begin{aligned}
& \hat{\mathbf{u}}=\sum_{j=1}^{n} \varphi_{j} u_{j}+\sum_{\alpha=1}^{n} \sum_{i=2}^{n l} \phi_{\alpha i} b_{\alpha i} \\
& \hat{\mathbf{v}}=\sum_{j=1}^{n} \varphi_{j} v_{j}+\sum_{\alpha=1}^{n} \sum_{i=2}^{n l} \phi_{\alpha i} c_{\alpha i}
\end{aligned}
$$

onde $u_{j}$ e $v_{j}$ são parâmetros associados aos graus de liberdade nodais usuais de elementos finitos e $b_{\alpha i}$ e $c_{\alpha i}$ são parâmetros nodais adicionais introduzidos pelo 
enriquecimento. Nota-se que a PU acaba por realizar a "costura" entre as funções de forma de cada nuvem para a definição da aproximação global.

A marcha de cálculos empregada para a determinação dos parâmetros nodais é a mesma utilizada no caso do MEF, contudo, as próprias relações (4.2) e (4.3) indicam que no caso do MEFG o enriquecimento implica no aparecimento de novas linhas e/ou colunas nas matrizes e vetores convencionais.

É importante ressaltar que quando as funções enriquecedoras da aproximação são polinomiais, e as funções de forma dos elementos finitos também o são, existe uma chance considerável das funções de forma geradas resultarem linearmente dependentes. Esse fato acaba proporcionando uma matriz de rigidez global que não apresenta a propriedade de ser positivo-definida. Uma maneira eficiente de resolver esse problema é escolher funções de enriquecimento que não sejam polinomiais ou empregar o algoritmo iterativo sugerido em Strouboulis, Babuška e Copps (2000).

\subsection{Um novo estimador de erro para o MEFG}

Como uma conseqüência natural do avanço das aplicações do MEFG nos últimos anos, tornou-se interessante a construção de estimadores de erro que permitissem avaliar e controlar o grau de precisão das respostas obtidas com esse método. Barros (2002) cita dois trabalhos em que esse tema é discutido, primeiramente em Babuška et al. (1998) e mais tarde em Strouboulis, Copps e Babuška (2001). No primeiro deles, segundo esse mesmo autor, discute-se, apenas, a eficiência de um estimador baseado em resíduo e de um estimador baseado em recuperação sem incorporá-los em um procedimento adaptativo. Em Strouboulis, Copps e Babuška (2001), por sua vez, de acordo com os próprios autores, os estimadores de erro são construídos a partir da generalização das idéias de Zienkiewicz e Zhu (1992a, 1992b), e Wiberg e Abdulwahab (1993), no contexto do MEFG. Naquele trabalho, ao contrário do que geralmente acontece, a função suavizada calculada é o campo de deslocamentos e não as tensões. Essa função suavizada é então usada dentro de um procedimento adaptativo. 
Os trabalhos citados no parágrafo anterior são alguns dos poucos exemplos, quando comparados ao MEF, que discutem o erro especificamente para o MEFG. Tendo em vista esse cenário, neste trabalho investiga-se a possibilidade de construção de um novo estimador de erro para o MEFG baseado nas idéias de recuperação do gradiente da solução contidas no SPR Modificado.

Em resumo, os campos suavizados de tensão são determinados com recurso ao SVD. Esse novo estimador é aqui denominado de Estimador do MEFG baseado no SPR Modificado, ou simplesmente, EPMEFG. O nível de precisão desse novo estimador é avaliado através do cálculo dos índices de efetividade para malhas de elementos quadrilaterais.

O propósito inicial do EPMEFG era simplesmente expandir as idéias do SPR Modificado para o contexto do MEFG. No entanto, logo se viu que essa expansão não seria tão simples, em virtude das funções de enriquecimento. Com o enriquecimento há possibilidade de que cada elemento dentro de uma mesma nuvem apresente um diferente campo de deslocamentos aproximado. Por conseguinte, nessa situação há uma grande chance de cada elemento da nuvem possuir um número diferente de pontos superconvergentes. Algo que nunca iria acontecer com o MEF convencional.

Outra conseqüência da presença de diferentes campos de deslocamentos aproximados dentro de uma mesma nuvem é a dúvida quanto ao grau do polinômio que representa o campo de tensões suavizadas dessa nuvem. No EPMEFG foi adotado que o grau desse polinômio é igual ao maior entre todos os polinômios que aproximam os deslocamentos dos elementos que compõem a nuvem. No entanto, existem ocasiões em que mais de um elemento possui o maior grau dos deslocamentos, porém esses deslocamentos são aproximados por polinômios com diferentes quantidades de termos. Em casos como esse, adota-se que o campo de tensões suavizadas tem a mesma quantidade de termos do deslocamento aproximado pelo polinômio com a maior quantidade de termos.

É essencial mencionar que o EPMEFG calcula a quantidade de pontos superconvergentes de um elemento de forma diferente do SPR Modificado. Nesse novo estimador, o número de pontos ótimos é exatamente igual à ordem do campo de deslocamentos aproximado do elemento. Vale lembrar que no SPR Modificado a quantidade de pontos superconvergentes é igual $(n d+1) / 2$, onde $n d$ se refere à 
ordem do campo de deslocamentos aproximado do elemento. Essa mudança aconteceu baseada em uma série de testes numéricos que demonstraram uma melhora dos resultados, apesar de que, precipitadamente, pode-se pensar que o EPMEFG utilize mais pontos superconvergentes do que o necessário.

Da mesma forma que acontece no SPR Modificado pode acontecer também no EPMEFG que alguma nuvem não tenha o número suficiente de pontos superconvergentes para calcular o campo de tensões suavizadas. Para superar esse entrave o novo estimador simplesmente não é calculado em nuvens cujo nó central faz parte do contorno da rede de elementos. O campo de tensões suavizadas dessas nuvens é calculado da mesma maneira como a descrita anteriormente para o SPR Modificado, isto é, empregando-se a aproximação obtida na nuvem interior mais próxima.

Uma vez calculados todos os campos de tensões suavizadas para todas as nuvens o próximo passo é obter uma distribuição para todo o conjunto de elementos. Em qualquer ponto de um elemento o valor global das tensões suavizadas resulta das contribuições das distribuições definidas nas nuvens que o contém, compatibilizadas pela partição da unidade atrelada aos nós do elemento em questão. Esse conceito pode ser representado pela seguinte relação:

$$
\boldsymbol{\sigma}^{*}=\mathbf{N} \boldsymbol{\sigma}_{\mathbf{p}}^{*}
$$

onde $\mathbf{N}$ é um vetor linha que reúne as funções de forma do elemento e que compõe uma PU. É importante destacar que a (4.4) vale para cada componente de tensão nos casos de problemas planos e os campos envolvidos $\left(\boldsymbol{\sigma}^{*}, \mathbf{N}\right.$ e $\left.\boldsymbol{\sigma}_{\mathbf{p}}^{*}\right)$ são funções de $x$ e $y$.

Enfim, a determinação do campo de tensões suavizadas com o EPMEFG é similar ao SPR Modificado, mas devido ao enriquecimento existem mudanças importantes. O roteiro a seguir descreve como o procedimento descrito calcula o campo de tensões suavizadas:

i. Separação dos nós que estão no contorno da rede de elementos finitos dos nós que estão no interior; 
ii. Determinação do número e localização dos pontos superconvergentes e identificação do grau e quantidade de termos do polinômio usado para aproximar as tensões dentro das nuvens;

iii. Cálculo de $\boldsymbol{\sigma}_{\mathbf{p}}^{*}(x, y)$, com a ajuda do SVD, nas nuvens cujos nós centrais são pontos interiores classificados em i, a partir da recuperação das respostas obtidas nos pontos ótimos com o MEFG;

iv. Identificação de qual nó interno está mais próximo de um determinado nó no contorno. Esse procedimento visa descobrir qual seria o polinômio $\boldsymbol{\sigma}_{\mathbf{p}}^{*}(x, y)$, determinado em um passo anterior, usado nas nuvens cujos nós centrais fazem parte do contorno de acordo com i;

v. Obtenção da distribuição global de tensões suavizadas com o auxílio da equação (4.4).

\subsubsection{Um exemplo unidimensional}

A característica principal deste exemplo é a variação cúbica assumida para o carregamento externo.
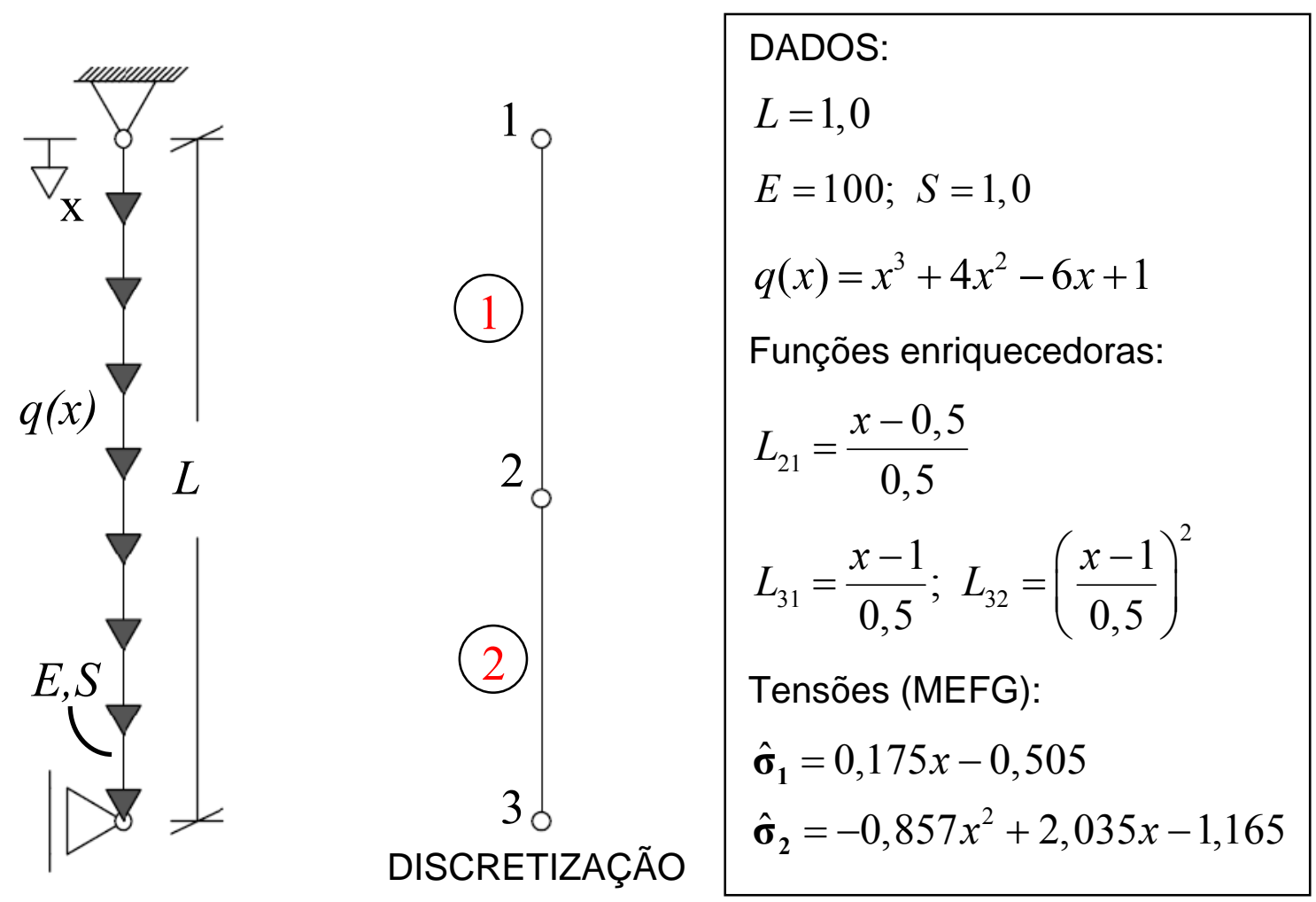

Figura 4.2 - Barra submetida a um carregamento cúbico (Exemplo 3) 
De acordo com o roteiro para o EPMEFG, considerando a malha de elementos ilustrada na Figura 4.2 a única nuvem que fornece um campo de tensões suavizadas é aquela cujo nó central é o nó 2. Logo, o primeiro passo é descobrir a quantidade e a localização dos pontos superconvergentes dessa nuvem.

A partir das tensões obtidas com o MEFG é possível afirmar que a ordem do campo de deslocamentos aproximados é 2 para o elemento 1 e 3 para o elemento 2 . Portanto, o elemento 1 tem 2 pontos superconvergentes e o elemento 2 tem 3. Esses pontos coincidem com os pontos de Gauss. Deste modo, as coordenadas desses pontos são:

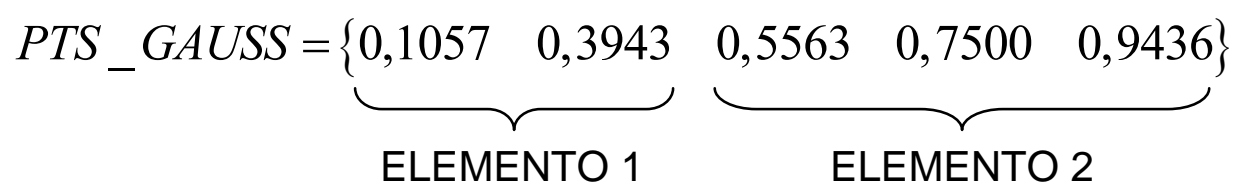

A etapa seguinte é calcular o polinômio que aproxima as tensões suavizadas dentro da nuvem. Esse polinômio precisa ter o mesmo grau de aproximação do campo de deslocamentos do elemento 2, uma vez que os deslocamentos aproximados desse elemento apresentam a maior ordem. Assim sendo, as tensões suavizadas são descritas por um polinômio cúbico completo, isto é:

$$
\boldsymbol{\sigma}_{\mathbf{p}, 2}^{*}(x)=\alpha_{1}+\alpha_{2} x+\alpha_{3} x^{2}+\alpha_{4} x^{3}
$$

Para calcular os coeficientes é montado o sistema da equação (3.10). Nesse caso, a matriz A é preenchida substituindo as coordenadas dos pontos de Gauss em $\boldsymbol{\sigma}_{\mathbf{p}, 2}^{*}(x)$, e o vetor $\hat{\boldsymbol{\sigma}}$ é calculado substituindo essas mesmas coordenadas nas respostas obtidas com o MEFG. O sistema é então solucionado com o auxílio do SVD, obtendo-se, conseqüentemente:

$$
\boldsymbol{\sigma}_{\mathbf{p}, 2}^{*}(x)=-0,3973-1,2031 x+3,5847 x^{2}-1,9840 x^{3}
$$

Seguindo o roteiro prescrito no EPMEFG, o passo subseqüente é obter o campo de tensões suavizadas para as nuvens cujo nós centrais estão no contorno. 
Nesse caso, as tensões nessas nuvens serão iguais àquelas presentes na nuvem 2, ou seja:

$$
\begin{aligned}
& \boldsymbol{\sigma}_{\mathbf{p}, 1}^{*}(x)=-0,3973-1,2031 x+3,5847 x^{2}-1,9840 x^{3} \\
& \boldsymbol{\sigma}_{\mathbf{p}, 3}^{*}(x)=-0,3973-1,2031 x+3,5847 x^{2}-1,9840 x^{3}
\end{aligned}
$$

Para gerar uma distribuição de tensões para todo o domínio emprega-se a equação (4.4). Portanto,

$$
\begin{aligned}
& \boldsymbol{\sigma}_{1}^{*}=N_{1}(x) \boldsymbol{\sigma}_{\mathbf{p}, 1}^{*}(x)+N_{2}(x) \boldsymbol{\sigma}_{\mathbf{p}, 2}^{*}(x)=-0,3973-1,2031 x+3,5847 x^{2}-1,9840 x^{3} \\
& \boldsymbol{\sigma}_{2}^{*}=N_{2}(x) \boldsymbol{\sigma}_{\mathbf{p}, 2}^{*}(x)+N_{3}(x) \boldsymbol{\sigma}_{\mathbf{p}, 3}^{*}(x)=-0,3973-1,2031 x+3,5847 x^{2}-1,9840 x^{3}
\end{aligned}
$$

As Figuras 4.3 e 4.4 apresentam uma comparação entre os três campos de tensões distintos: aproximado $\hat{\boldsymbol{\sigma}}$ (MEFG), suavizado $\boldsymbol{\sigma}^{*}$ (EPMEFG) e exato $\boldsymbol{\sigma}$.

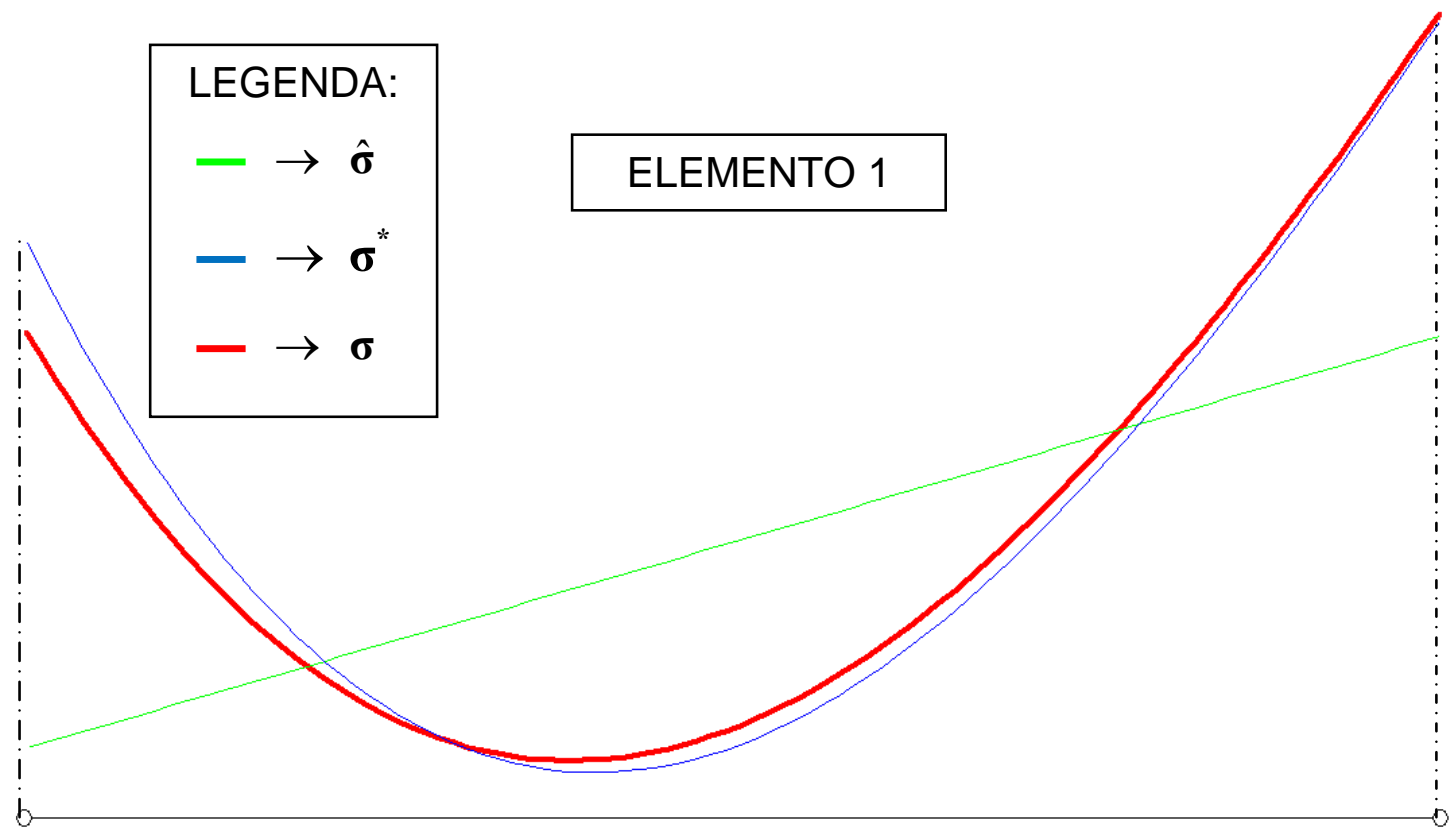

Figura 4.3 - Comparação entre os diferentes campos de tensões do elemento 1 (Exemplo 3) 


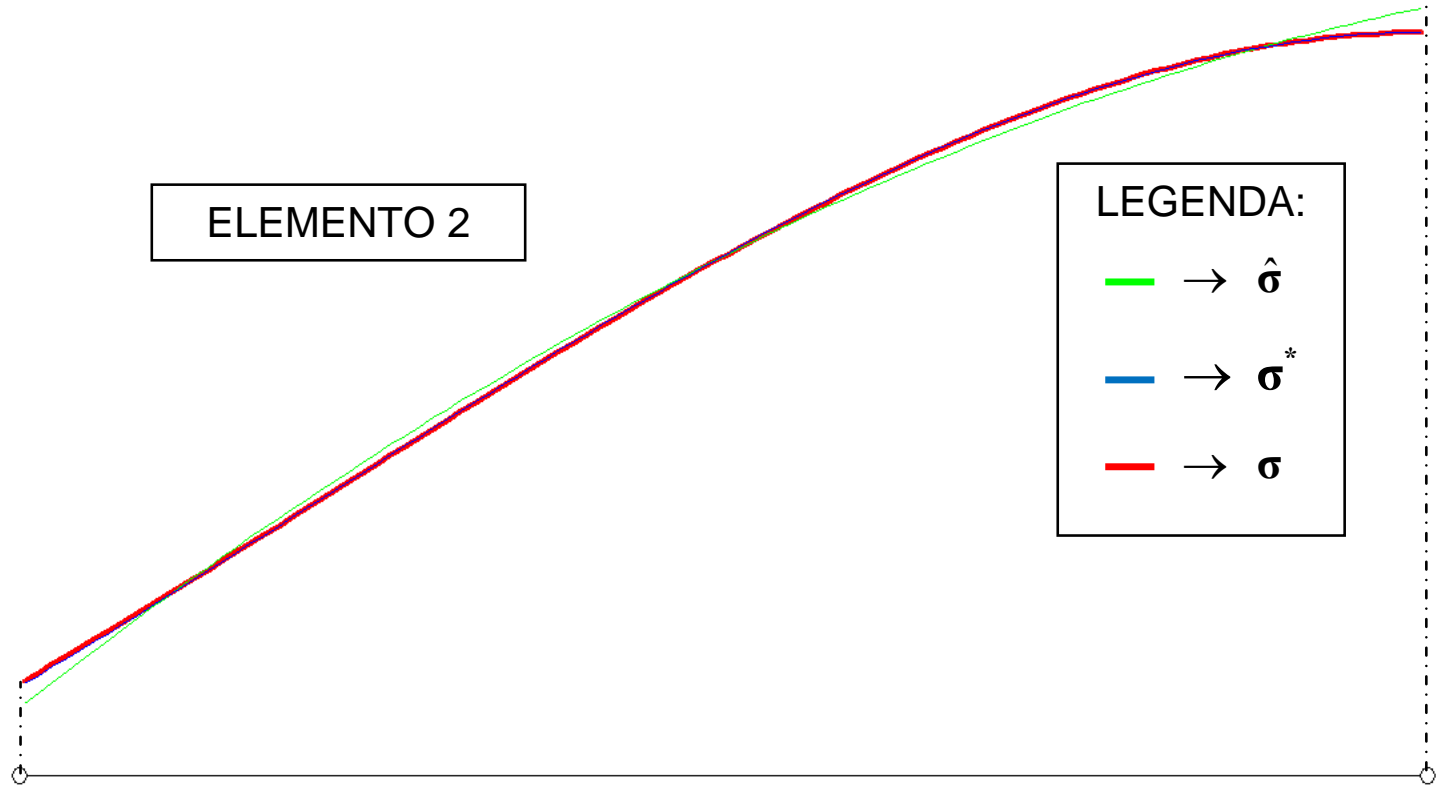

Figura 4.4 - Comparação entre os diferentes campos de tensões do elemento 2 (Exemplo 3)

É importante observar que no segundo elemento a tensão calculada com o EPMEFG praticamente coincide com a tensão exata. 


\section{EXEMPLOS NUMÉRICOS}

Uma vez detalhados os estimadores de erro estudados neste trabalho, o próximo passo naturalmente é mostrar os resultados obtidos com cada um deles em diferentes situações. Para alcançar esses resultados foi desenvolvido um programa computacional. Este capítulo inicialmente enumera algumas características desse programa para em seguida apresentar uma série de exemplos resolvidos com o mesmo. Esses exemplos estão divididos em dois grupos. Primeiramente, o estimador Z e o SPR Modificado são empregados em problemas resolvidos com o MEF. Em seguida, o EPMEFG é aplicado em problemas resolvidos com o MEFG. A eficiência de todos os estimadores é avaliada através do índice de efetividade.

\subsection{Descrição resumida do programa computacional desenvolvido}

A implementação computacional das estratégias de erro desenvolvida como parte fundamental deste trabalho foi elaborada em linguagem Fortran. Procurou-se seguir os preceitos da programação orientada a objetos, embora a versão utilizada do Fortran, que no caso foi a versão Fortran 95, não disponibilize de recursos específicos para esse tipo de programação. Sendo assim, foi necessária uma série de adaptações para contornar essa situação.

O programa resultante na verdade é dividido em dois subprogramas. $O$ primeiro, denominado PEAZERM2D, trata dos estimadores de erro desenvolvidos para o MEF e o segundo, denominado SMEFG_2D, está relacionado ao estimador de erro do MEFG.

O PEAZERM2D tem a capacidade de trabalhar com três tipos distintos de elementos. O primeiro deles é a barra de treliça com dois nós e um grau de liberdade por nó. O segundo são os elementos triangulares lineares que possuem três nós e dois graus de liberdade por nó. O terceiro são os elementos quadrilaterais bilineares que possuem quatro nós e dois graus de liberdade por nó.

O algoritmo implementado no PEAZERM2D basicamente é o seguinte: 
1. Leitura do arquivo de entrada que contém os dados da estrutura, tipo de elemento e de estimador de erro (Estimador Z ou SPR Modificado);

2. Análise da estrutura através do MEF convencional;

3. Análise de erro a posteriori com o auxílio do estimador escolhido;

3.1 Determinação dos valores nodais suavizados;

3.2 Determinação do campo de tensões suavizadas para todo o domínio;

3.3 Determinação do campo de tensões exato;

3.4 Cálculo do estimador do erro pelas normas energia e $L_{2}$;

3.5 Cálculo dos índices de efetividade;

4. Armazenamento dos resultados obtidos em um arquivo texto.

O SMEFG_2D, por sua vez, trabalha atualmente na análise do erro apenas com elementos quadrilaterais bilineares isoparamétricos que possuem quatro nós e dois graus de liberdade por nó. Um diferencial do SMEFG_2D é que ele permite que os diferentes campos de tensões calculados sejam plotados com o auxílio do AcadView (PACCOLA; CODA, 2005), software livre para pós-processamento em elementos finitos 2D e 3D.

O algoritmo implementado no SMEFG_2D basicamente é o seguinte:

1. Leitura do arquivo de entrada que contém os dados da estrutura e as funções enriquecedoras;

2. Análise da estrutura através do MEFG;

3. Definição da solução de referência (viga engastada ou biapoiada) usada para calcular os índices de efetividade;

4. Montagem de todas as nuvens;

5. Análise de erro a posteriori com o auxílio do estimador EPMEFG;

5.1 Determinação dos campos de tensões suavizados para todas as nuvens;

5.2 Determinação do campo de tensões suavizadas para todo o domínio;

5.3 Cálculo do erro estimado através das normas energia e $L_{2}$;

5.4 Cálculo do erro exato através das normas energia e $L_{2}$;

5.5 Cálculo dos índices de efetividade;

6. Armazenamento dos resultados obtidos em dois arquivos texto, sendo que um deles é usado para alimentar a visualização com o AcadView dos diferentes campos de tensões. 


\subsection{Estimadores Z e SPR Modificado}

Para verificar a precisão da ferramenta numérica PEAZERM2D foi analisado o problema da viga engastada com carregamento em sua extremidade livre, ilustrado na Figura 5.1. Esse problema dispõe dos mesmos dados de um exemplo similar proposto em Zienkiewicz e Zhu (1987) e foi aqui resolvido por diferentes malhas.

A primeira malha de elementos quadrilaterais bilineares testada, com seus respectivos índices de efetividade locais calculados com o Estimador Z, está ilustrada na Figura 5.2. Os índices mostrados nessa figura foram calculados pela norma energia empregando-se a solução analítica baseada na elasticidade linear disponibilizada em Barber (2002). Observa-se que os índices obtidos são praticamente coincidentes com os que aparecem no exemplo resolvido em Zienkiewicz e Zhu (1987), sendo as diferenças provavelmente causadas pela forma na qual as condições de contorno foram impostas neste trabalho.

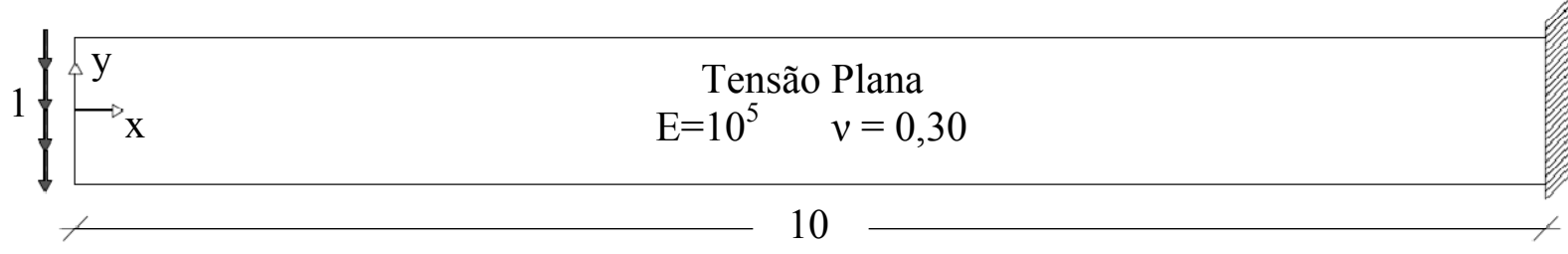

Figura 5.1 - Dados do problema resolvido com o PEAZERM2D

Para verificar se o Estimador Z e o SPR Modificado são assintoticamente exatos foi aplicado um refinamento uniforme progressivo partindo da malha ilustrada na Figura 5.2. Foram geradas tanto malhas de elementos quadrilaterais bilineares como de elementos finitos triangulares lineares. O refinamento adotado é mostrado na Figura 5.3, indicando-se as divisões sucessivas quadrilaterais ou triangulares impostas a um elemento típico como o sombreado na Figura 5.2.

\begin{tabular}{|l|l|l|l|l|l|l|l|l|l|}
\hline 0,68 & 0,80 & 0,80 & 0,80 & 0,80 & 0,81 & 0,79 & 0,78 & 0,90 & 0,57 \\
\hline
\end{tabular}

Figura 5.2 - Índices de efetividade locais do problema da Figura 5.1 calculados com a norma energia 


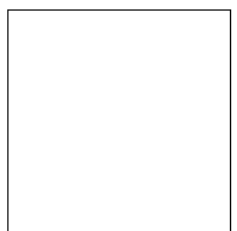

MALHA 1

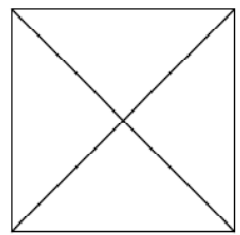

MALHA 2

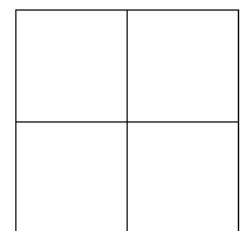

MALHA 3

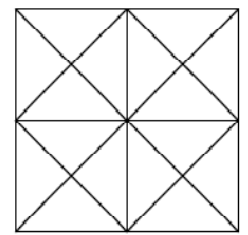

MALHA 4

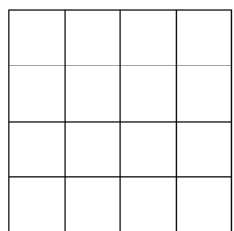

MALHA 5

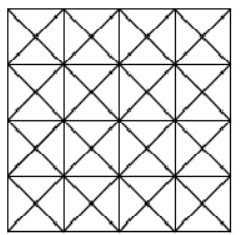

MALHA 6

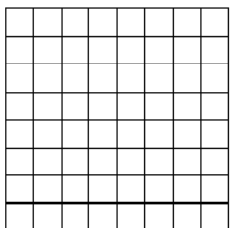

MALHA 7

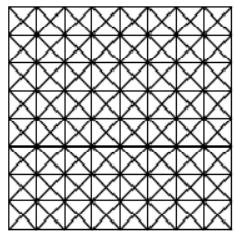

MALHA 8

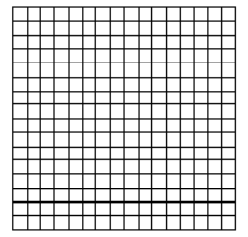

MALHA 9

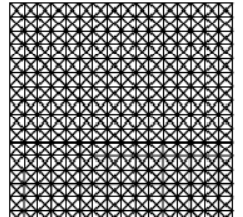

MALHA 10

Figura 5.3 - Refinamento progressivo aplicado para verificar se os estimadores estudados são assintoticamente exatos

As Tabelas 5.1 e 5.2 apresentam os índices de efetividade globais calculados para todas as malhas. É importante mencionar que esses valores foram calculados desprezando os índices de efetividade locais que estavam fora de determinados intervalos de tolerância. Essa atitude foi tomada para desconsiderar perturbações de contorno, uma vez que a solução numérica perde representatividade por conta da diferença com a condição de contorno da solução exata nos elementos próximos ao engaste e a extremidade livre. Em suma, os índices de efetividade locais só participavam do cálculo do índice de efetividade global se estivessem dentro dos seguintes intervalos:

- $0,80<\theta<1,20$ (Norma energia);

- $0,70<\theta<1,30\left(\right.$ Norma $\left.\mathrm{L}_{2}\right)$.

Além disso, ficou estabelecido ainda que a quantidade máxima de elementos desprezados (com índice de efetividade fora dos intervalos supracitados) era 25\% do número total de elementos. Essa medida é responsável pela ausência das malhas 1 e 2 nas tabelas a seguir. 
Tabela 5.1 - Índices de efetividade globais das malhas de elementos quadrilaterais

\begin{tabular}{|c|c|c|c|c|c|}
\cline { 3 - 6 } & \multirow{2}{*}{$\begin{array}{c}N^{\circ} \text { de } \\
\text { graus de } \\
\text { liberdade }\end{array}$} & \multicolumn{4}{|c|}{ Índices de efetividade globais } \\
\cline { 3 - 6 } \multicolumn{1}{c|}{} & & \multicolumn{2}{|c|}{ Norma energia } & \multicolumn{2}{c|}{ Norma $\mathrm{L}_{2}$} \\
\cline { 3 - 6 } & Estimador Z & SPR Modificado & Estimador Z & SPR Modificado \\
\hline MALHA 3 & 120 & 0,9279 & 0,9199 & 0,8945 & 0,9047 \\
\hline MALHA 5 & 400 & 0,9757 & 0,9780 & 0,9574 & 0,9743 \\
\hline MALHA 7 & 1440 & 0,9864 & 0,9948 & 0,9738 & 0,9856 \\
\hline MALHA 9 & 5440 & 0,9914 & 0,9947 & 0,9850 & 0,9888 \\
\hline
\end{tabular}

Tabela 5.2 - Índices de efetividade globais das malhas de elementos triangulares

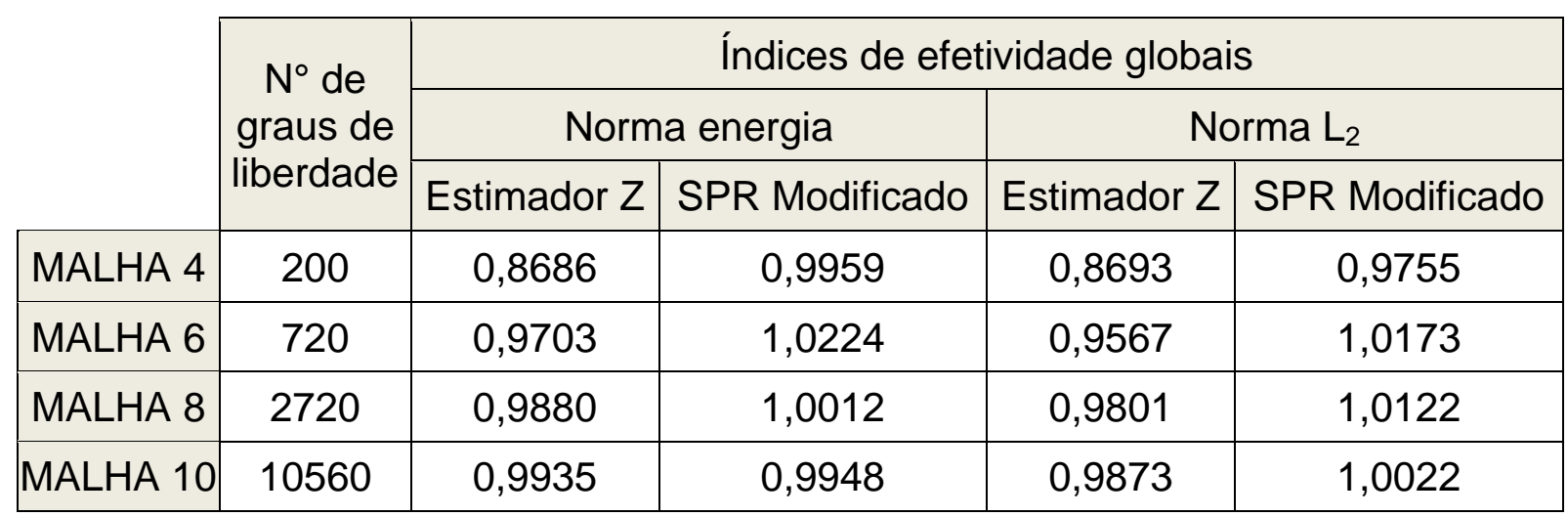

As Figuras 5.4 e 5.5 indicam em gráficos o que acontece com os índices de efetividade globais à proporção em que se aumenta o número de graus de liberdade.

Portanto, a partir dos resultados obtidos pode-se afirmar que tanto 0 Estimador Z quanto o SPR Modificado são assintoticamente exatos, ou seja, os dois estimadores convergem para o erro exato à medida que a densidade da malha é aumentada. Isso fica claro nos gráficos das Figuras 5.4 e 5.5, pois com o refinamento da malha todas as curvas tendem ao índice de efetividade unitário. Além disso, nota-se uma diferença significativa entre os resultados alcançados com cada estimador nas malhas mais grosseiras de elementos triangulares, sendo que os resultados do estimador SPR Modificado apresentam índice muito bom desde a primeira malha decorrente, provavelmente, de sua forma de ajuste proporcionada pelo SVD. 


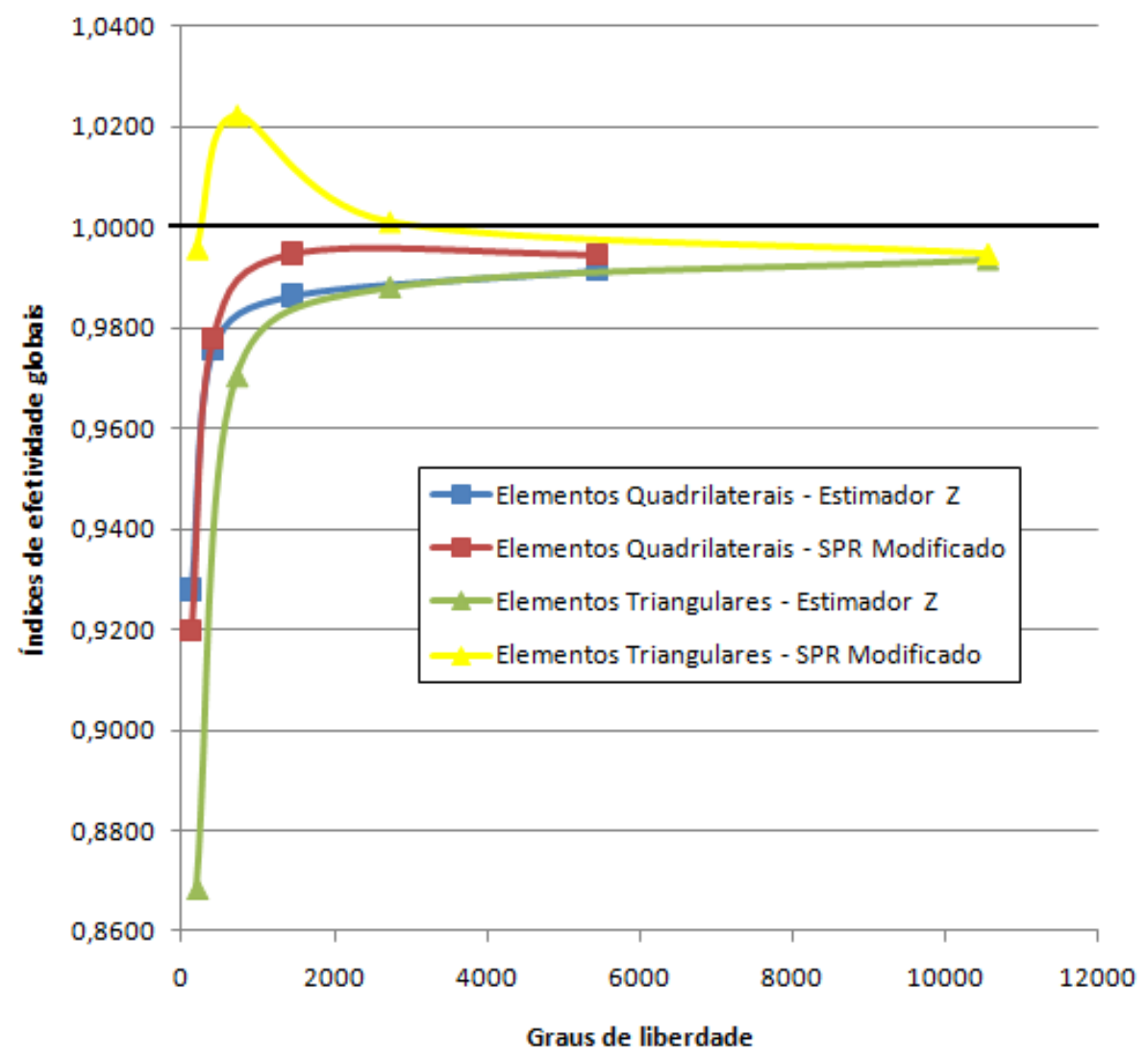

Figura 5.4 - Índices de efetividade globais calculados com a norma energia

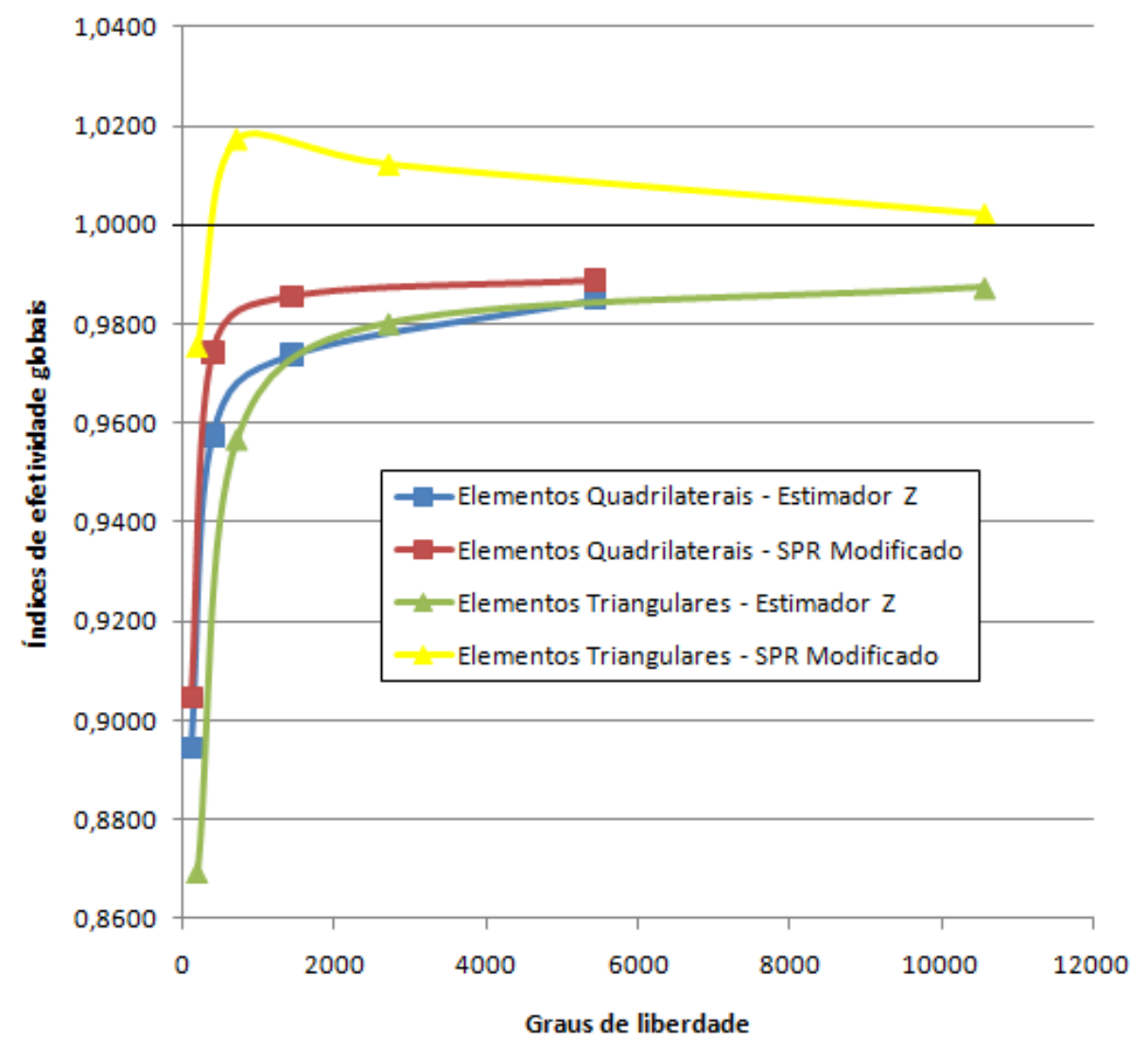

Figura 5.5 - Índices de efetividade globais calculados com a norma $L_{2}$ 


\subsection{EPMEFG}

Para averiguar a precisão do SMEFG_2D foram analisados dois diferentes problemas. O primeiro deles consiste em viga engastada com carregamento em sua extremidade livre (Figura 5.6). O segundo consiste em viga biapoiada com carregamento distribuído ao longo de seu comprimento (Figura 5.7). Ambos os problemas foram discretizados por uma mesma malha regular bastante grosseira de elementos quadrilaterais bilineares. Essa malha é ilustrada tanto na Figura 5.6 quanto na Figura 5.7.

\begin{tabular}{|c|c|c|c|c|c|c|c|c|c|c|c|c|c|c|c|c|c|c|c|}
\hline 21 & 22 & 23 & 24 & 25 & 26 & 27 & 28 & 29 & 30 & 31 & 32 & 33 & 34 & 35 & 36 & 37 & 38 & 39 & 40 \\
\hline 01 & 02 & 03 & 04 & 05 & 06 & 07 & 08 & 09 & 10 & 11 & 12 & 13 & 14 & 15 & 16 & 17 & 18 & 19 & 20 \\
\hline
\end{tabular}

Figura 5.6 - Viga engastada - tensão plana - E $=10^{4}, v=0,25$

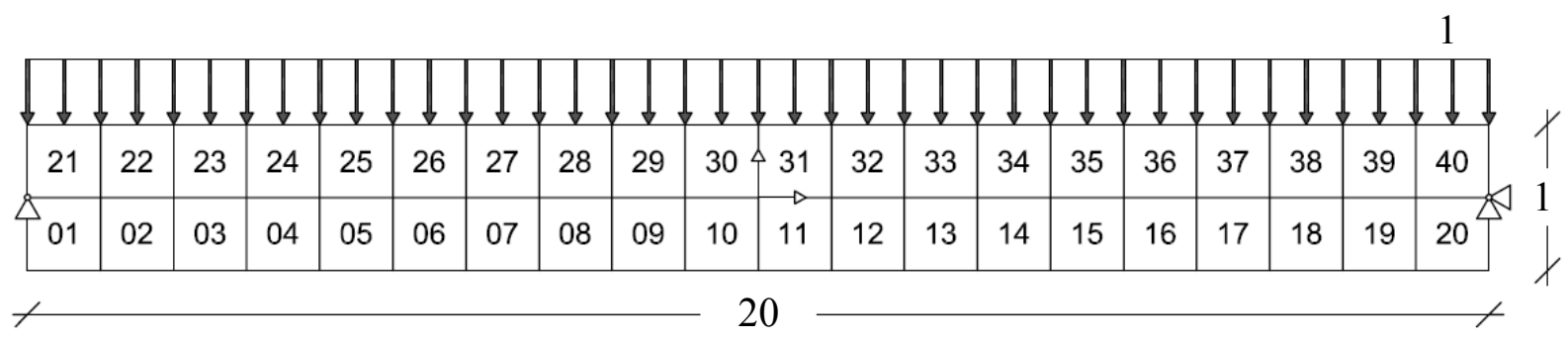

Figura 5.7 - Viga biapoiada - tensão plana - $\mathrm{E}=10^{4}, v=0,25$

Inicialmente procurou-se avaliar o efeito do enriquecimento nos valores dos índices de efetividade. Mais uma vez a solução analítica baseada na elasticidade linear usada para calcular os índices foi obtida em Barber (2002). As Tabelas 5.3 e 5.4 apresentam uma comparação dos índices calculados empregando-se os valores recuperados com o procedimento descrito nas situações sem enriquecimento (MEF) e com enriquecimento (MEFG). A determinação dos índices de efetividade globais em ambas as tabelas é realizada usando o mesmo critério discutido na página 72 deste trabalho. 
Tabela 5.3 - Comparação entre os índices de efetividade calculados empregando-se os valores recuperados com o EPMEFG nas situações sem enriquecimento (MEF) e com enriquecimento (MEFG) para viga engastada

\begin{tabular}{|c|c|c|c|c|c|c|c|c|c|}
\hline \multirow[b]{3}{*}{ Elem. } & \multicolumn{4}{|c|}{ Índices de efetividade locais } & \multirow[b]{3}{*}{ Elem. } & \multicolumn{4}{|c|}{ Índices de efetividade locais } \\
\hline & \multicolumn{2}{|c|}{ Norma energia } & \multicolumn{2}{|c|}{ Norma L2 } & & \multicolumn{2}{|c|}{ Norma energia } & \multicolumn{2}{|c|}{ Norma L2 } \\
\hline & MEF & MEFG & MEF & MEFG & & MEF & MEFG & MEF & MEFG \\
\hline 1 & 0,7000 & 0,9262 & 0,6897 & 0,8856 & 21 & 0,7000 & 0,9262 & 0,6897 & 0,8856 \\
\hline 2 & 0,8073 & 1,0022 & 0,7162 & 1,0020 & 22 & 0,8073 & 1,0022 & 0,7162 & 0020 \\
\hline 3 & 0,8273 & 1,0003 & 0,7221 & 1,0000 & 23 & 0,8273 & 1,0003 & 0,7221 & 1,0000 \\
\hline 4 & 0,8334 & 0,9999 & 0,7243 & 0,9998 & 24 & 0,8334 & 0,9999 & 0,7243 &, 9998 \\
\hline 5 & 0,8360 & 1,0000 & 0,7253 & 1,0000 & 25 & 0,8360 & 1,0000 & 0,7253 & 1,0000 \\
\hline 6 & 0,8374 & 1,0000 & 0,7258 & 1,0000 & 26 & 0,8374 & 1,0000 & 0,7258 & 1,0000 \\
\hline 7 & 0,8382 & 1,0000 & 0,7261 & 1,0000 & 27 & 0,8382 & 1,0000 & 0,7261 & 1,0000 \\
\hline 8 & 0,8387 & 1,0000 & 0,7263 & 1,0000 & 28 & 0,8387 & 1,0000 & 0,7263 & 1,0000 \\
\hline 9 & 0,8390 & 1,0000 & 0,7264 & 0000 & 29 & 0,8390 & 1,0000 & 0,7264 & 0000 \\
\hline 10 & 0,8392 & 1,0000 & 0,7265 & 1,0000 & 30 & 0,8392 & 1,0000 & 0,7265 & 1,0000 \\
\hline 11 & 0,8394 & 1,0000 & 0,7266 & 1,0000 & 31 & 0,8394 & 1,0000 & 0,7266 & 1,0000 \\
\hline 12 & 0,8395 & 00 & 0,7266 & 00 & 32 & 0 & 0 & 6 & 000 \\
\hline 13 & 0,8396 & 1,0000 & 0,7266 & 0,9999 & 33 & 0,8396 & 1,0000 & 0,7266 & 0,9999 \\
\hline 14 & 0,8397 & 1,0001 & 0,7267 & 1,0003 & 34 & 0,8397 & 1,0001 & 0,7267 & 1,0003 \\
\hline 15 & 0,8398 & 0,9998 & 0,7267 & 0,9989 & 35 & 0,8398 & 98 & 0,7267 & 0,9989 \\
\hline 16 & 0,8397 & 0,9999 & 0,7266 & 1,0019 & 36 & 0,8397 & 0,9999 & 0,7266 & 1,0019 \\
\hline 17 & 0,8401 & 0,9918 & 0,7270 & 0 , & 37 & 0,8401 & 0,9918 & 0,7270 & 0,9744 \\
\hline 18 & 0,8388 & 0,9416 & 0,7259 & 0,9258 & 38 & 0,8388 & 0,9416 & 0,7259 & 0,9258 \\
\hline 19 & 0,8452 & 1,1323 & 0,7328 & 1,1173 & 39 & 0,8452 & 1,1323 & 0,7328 & 1,1173 \\
\hline 2 & 0,8115 & 0,4966 & 0,6945 & 0,5 & 40 & 0,8115 & 0,4966 & 0,6945 & 0,5052 \\
\hline & \multirow{4}{*}{\multicolumn{4}{|c|}{ Índice de efetividade global }} & \multirow{2}{*}{\multicolumn{2}{|c|}{ Norma energia }} & \multicolumn{2}{|c|}{ MEF } & 0,8361 \\
\hline & & & & & & & \multicolumn{2}{|c|}{ MEFG } & 1,0627 \\
\hline & & & & & \multirow{2}{*}{\multicolumn{2}{|c|}{ Norma }} & \multicolumn{2}{|c|}{ MEF } & 0,7274 \\
\hline & & & & & & & \multicolumn{2}{|c|}{ MEFG } & 1,0766 \\
\hline
\end{tabular}


Tabela 5.4 - Comparação entre os índices de efetividade calculados empregando-se os valores recuperados com o EPMEFG nas situações sem enriquecimento (MEF) e com enriquecimento (MEFG) para viga biapoiada

\begin{tabular}{|c|c|c|c|c|c|c|c|c|c|}
\hline \multirow[b]{3}{*}{ Elem. } & \multicolumn{4}{|c|}{ Índices de efetividade locais } & & \multicolumn{4}{|c|}{ Índices de efetividade locais } \\
\hline & \multicolumn{2}{|c|}{ Norma energia } & \multicolumn{2}{|c|}{ Norma $L_{2}$} & \multirow[b]{2}{*}{ Elem. } & \multicolumn{2}{|c|}{ Norma energia } & \multicolumn{2}{|c|}{ Norma $L_{2}$} \\
\hline & MEF & MEFG & MEF & MEFG & & MEF & MEFG & MEF & MEFG \\
\hline 1 & 0,6891 & 0,9624 & 0,6646 & 0,9475 & 21 & 0,6891 & 0,9624 & 0,6646 & 0,9475 \\
\hline 2 & 0,8142 & 0,9667 & 0,7143 & 0,9366 & 22 & 0,8142 & 0,9667 & 0,7143 & 0,9366 \\
\hline 3 & 0,8303 & 0,9773 & 0,7224 & 0,9414 & 23 & 0,8303 & 0,9773 & 0,7224 & 0,9414 \\
\hline 4 & 0,8360 & 0,9755 & 0,7244 & 0,9397 & 24 & 0,8360 & 0,9755 & 0,7244 & 0,9397 \\
\hline 5 & 0,8380 & 0,9761 & 0,7253 & 0,9406 & 25 & 0,8380 & 0,9761 & 0,7253 & 0,9406 \\
\hline 6 & 0,8391 & 0,9763 & 0,7258 & 0,9410 & 26 & 0,8391 & 0,9763 & 0,7258 & 0,9410 \\
\hline 7 & 0,8396 & 0,9771 & 0,7261 & 0,9423 & 27 & 0,8396 & 0,9771 & 0,7261 & 0,9423 \\
\hline 8 & 0,8399 & 0,9788 & 0,7262 & 0,9450 & 28 & 0,8399 & 0,9788 & 0,7262 & 0,9450 \\
\hline 9 & 0,8401 & 0,9842 & 0,7263 & 0,9532 & 29 & 0,8401 & 0,9842 & 0,7263 & 0,9532 \\
\hline 10 & 0,8401 & 1,0099 & 0,7263 & 0,9870 & 30 & 0,8401 & 1,0099 & 0,7263 & 0,9870 \\
\hline 11 & 0,8401 & 1,0099 & 0,7263 & 0 , & 31 & 1 & 9 & 7263 & 9870 \\
\hline 12 & 0,8401 & 0,9842 & 0,7263 & 0,9532 & 32 & 0,8401 & 0,9842 & 0,7263 & 0,9532 \\
\hline 13 & 0,8399 & 0,9788 & 0,7262 & 0,9450 & 33 & 0,8399 & 0,9788 & 0,7262 & 0,9450 \\
\hline 14 & 0,8396 & 0,9771 & 0,7261 & 0,9423 & 34 & 0,8396 & 0,9771 & 0,7261 & 0,9423 \\
\hline 15 & 0,8391 & 0,9763 & 0,7258 & 0,9410 & 35 & 0,8391 & 0,9763 & 0,7258 & 0,9410 \\
\hline 16 & 380 & 0 , & 0 & 0 , & 36 & 30 & 1 & 3 & 0,9406 \\
\hline 17 & 0,8360 & 0,9755 & 0,7244 & 0,9397 & 37 & 0,8360 & 0,9755 & 0,7244 & 0,9397 \\
\hline 18 & 0,8303 & 0,9773 & 0,7224 & 0,9414 & 38 & 0,8303 & 0,9773 & 0,7224 & 0,9414 \\
\hline 19 & 0,8142 & 0,9667 & 0,7143 & 0,9366 & 39 & 0,8142 & 0,9667 & 0,7143 & 0,9366 \\
\hline 20 & 0,6891 & 0,9624 & 0,6646 & 0,9475 & 40 & 0,6891 & 0,9624 & 0,6646 & 0,9475 \\
\hline \multirow{4}{*}{\multicolumn{5}{|c|}{ Índice de efetividade global }} & \multirow{2}{*}{\multicolumn{2}{|c|}{ Norma energia }} & \multicolumn{2}{|c|}{ MEF } & 0,8386 \\
\hline & & & & & & & \multicolumn{2}{|c|}{ MEFG } & 0,9676 \\
\hline & & & & & \multirow{2}{*}{\multicolumn{2}{|c|}{ Norma $L_{2}$}} & \multicolumn{2}{|c|}{ MEF } & 0,7256 \\
\hline & & & & & & & \multicolumn{2}{|c|}{ MEFG } & 0,9 \\
\hline
\end{tabular}


Como esperado o enriquecimento faz com que os índices se aproximem bem mais da unidade, que seria a situação ideal. Cabe ressaltar que os resultados indicados para o MEFG foram obtidos no problema da viga engastada a partir do enriquecimento de todos os nós nas duas direções com as seguintes funções:

$$
L_{\alpha 1}=\frac{x-x_{\alpha}}{h} ; L_{\alpha 2}=\frac{y-y_{\alpha}}{h}
$$

No problema da viga biapoiada os enriquecimentos nodais foram:

$$
\begin{aligned}
& L_{\alpha 1}=\frac{x-x_{\alpha}}{h} ; L_{\alpha 2}=\frac{y-y_{\alpha}}{h} ; L_{\alpha 3}=\left(\frac{x-x_{\alpha}}{h}\right)\left(\frac{y-y_{\alpha}}{h}\right) \\
& L_{\alpha 4}=\left(\frac{x-x_{\alpha}}{h}\right)^{2} ; L_{\alpha 5}=\left(\frac{y-y_{\alpha}}{h}\right)^{2}
\end{aligned}
$$

Nas funções enriquecedoras das equações (5.1) e (5.2) $\left(x_{\alpha}, y_{\alpha}\right)$ são as coordenadas do nó enriquecido e $h$ é uma dimensão característica da nuvem da qual esse nó é centro.

Observa-se que os enriquecimentos adotados em (5.1) e (5.2), junto com a unidade, constituem por si só polinômios lineares e quadráticos, respectivamente.

Uma vez comprovado que a técnica de recuperação proposta para o MEFG permite obter bons índices de efetividade, o próximo passo consiste em analisar a distribuição das tensões recuperadas. As Figuras 5.8, 5.9 e 5.10 estão relacionadas ao problema da viga engastada. Por sua vez, as Figuras 5.11, 5.12 e 5.13 estão relacionadas ao problema da viga biapoiada. Nessas figuras são ilustrados os diferentes campos de tensões, separados em suas componentes, determinados com o MEFG, recuperadas com o EPMEFG e obtidos com a resposta exata. 


\section{Legenda:}

120.00000

93.33333

66.66667

40.00000

13.33333

$-13.33333$

$-40.00000$

$-66.66667$

$-93.33333$

$-120.00000$

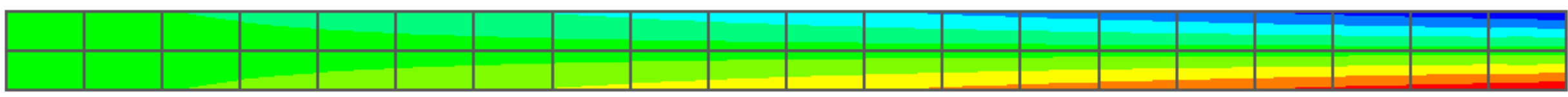

(a) Solução obtida com o MEFG

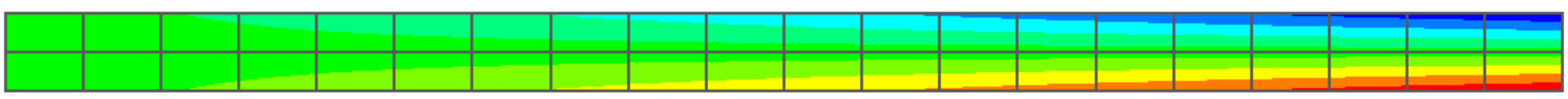

(b) Solução obtida com o EPMEFG (tensões recuperadas)

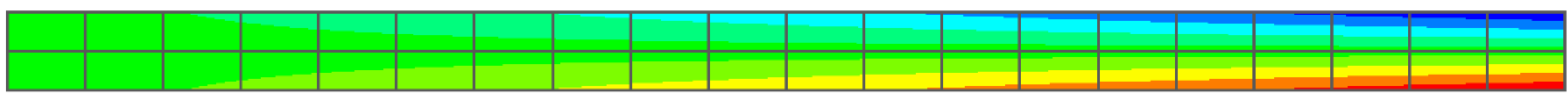

(c) Solução exata

Figura 5.8 - Componente $\sigma_{x}$ do campo de tensões calculada com o MEFG (a), com o EPMEFG (b) e pela resposta exata (c) para a viga engastada 


\section{Legenda:}

30.00000

23.33333

16.66667

10.00000

3.33333

$-3.33333$

$-10.00000$

$-16.66667$

$-23.33333$

$-30.00000$

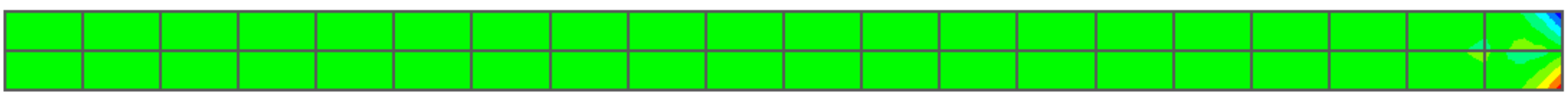

(a) Solução obtida com o MEFG

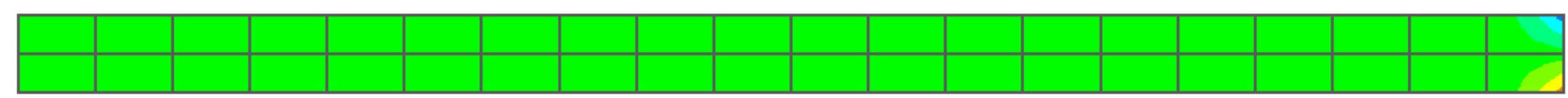

(b) Solução obtida com o EPMEFG (tensões recuperadas)

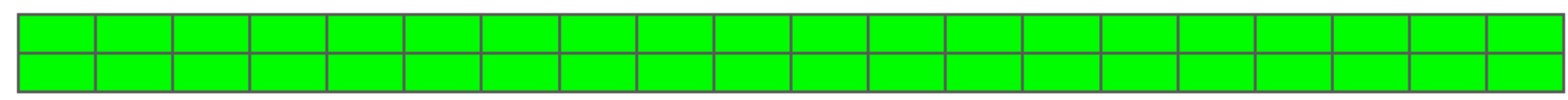

(c) Solução exata

Figura 5.9 - Componente $\sigma_{y}$ do campo de tensões calculada com o MEFG (a), com o EPMEFG (b) e pela resposta exata (c) para a viga engastada 


\section{Legenda:}

1.50000

1.33333

1.16667

1.00000

0.83333

0.66667

0.50000

0.33333

0.16667

0.00000

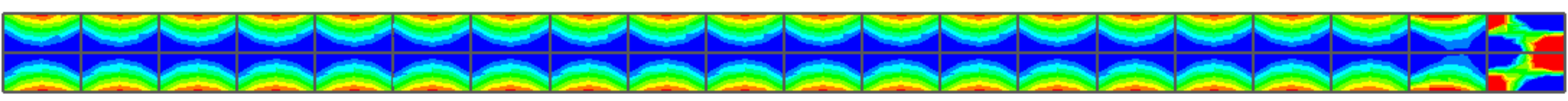

(a) Solução obtida com o MEFG

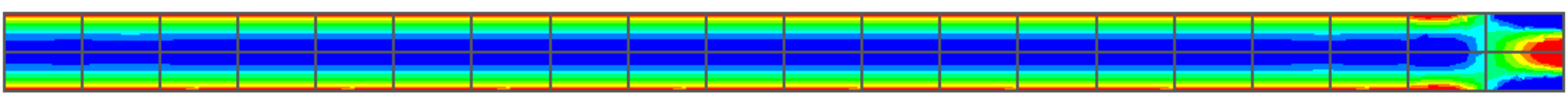

(b) Solução obtida com o EPMEFG (tensões recuperadas)

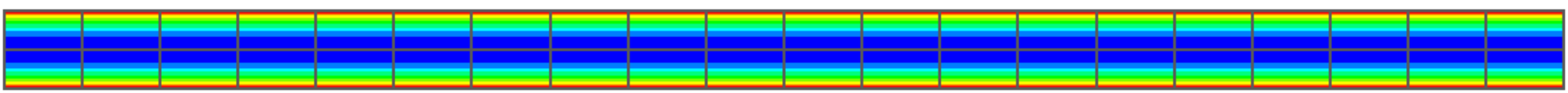

(c) Solução exata

Figura 5.10 - Componente $\tau_{x y}$ do campo de tensões calculada com o MEFG (a), com o EPMEFG (b) e pela resposta exata (c) para a viga engastada 


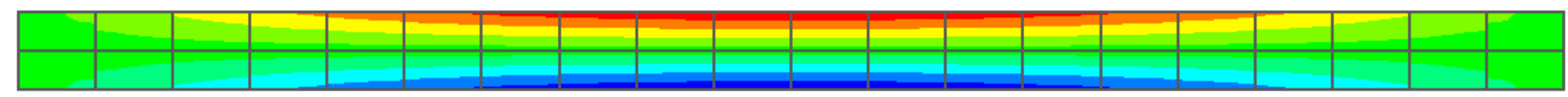

(a) Solução obtida com o MEFG

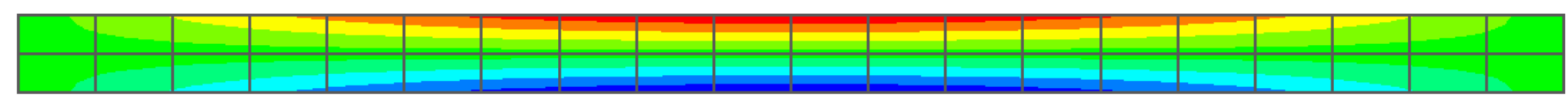

(b) Solução obtida com o EPMEFG (tensões recuperadas)

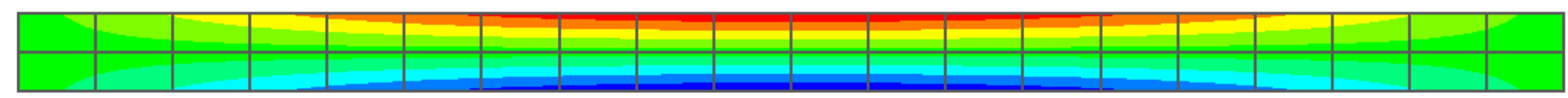

(c) Solução exata

Figura 5.11 - Componente $\sigma_{x}$ do campo de tensões calculada com o MEFG (a), com o EPMEFG (b) e pela resposta exata (c) para a viga biapoiada 


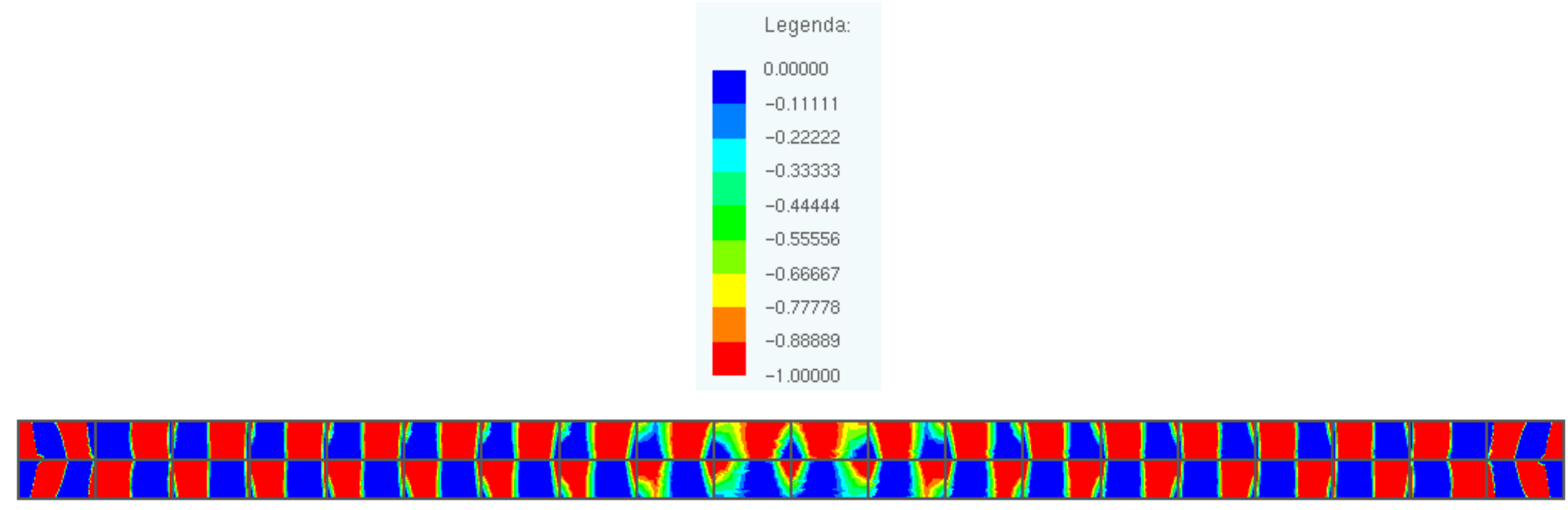

(a) Solução obtida com o MEFG

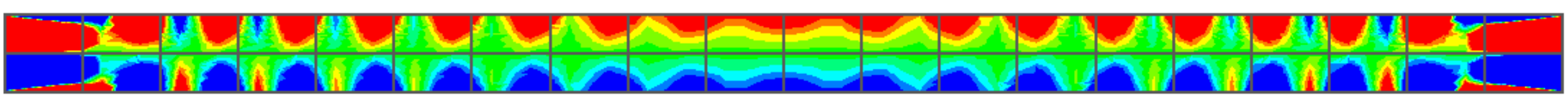

(b) Solução obtida com o EPMEFG (tensões recuperadas)

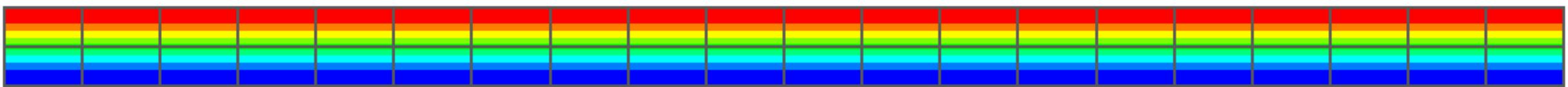

(c) Solução exata

Figura 5.12 - Componente $\sigma_{y}$ do campo de tensões calculada com o MEFG (a), com o EPMEFG (b) e pela resposta exata (c) para a viga biapoiada 


\section{Legenda:}

15.00000

11.66667

8.33333

5.00000

1.66667

$-1.66667$

$-5.00000$

$-8.33333$

$-11.66667$

$-15.00000$

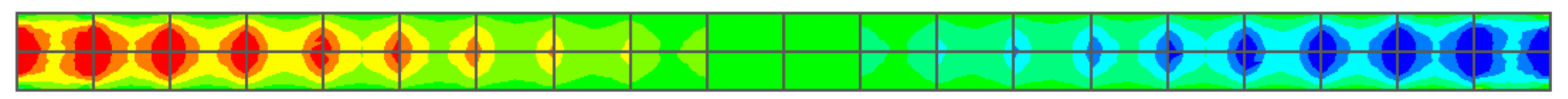

(a) Solução obtida com o MEFG

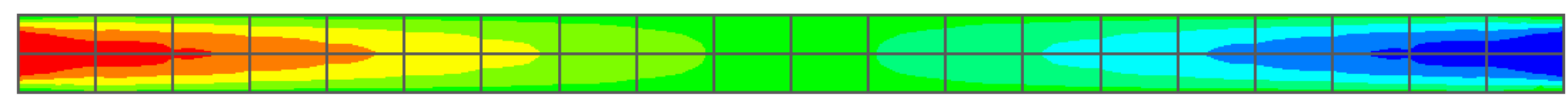

(b) Solução obtida com o EPMEFG (tensões recuperadas)

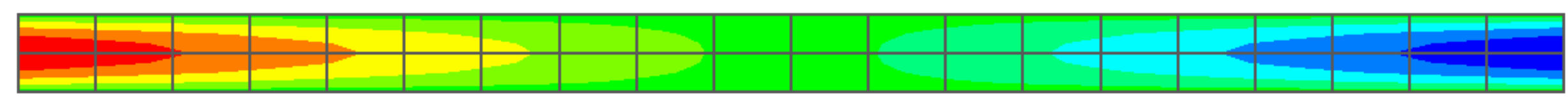

(c) Solução exata

Figura 5.13 - Componente $\tau_{x y}$ do campo de tensões calculada com o MEFG (a), com o EPMEFG (b) e pela resposta exata (c) para a viga biapoiada 
Na Figura 5.8 claramente percebe-se que a resposta do MEFG já apresenta um nível de precisão considerável, portanto, o EPMEFG praticamente não altera a resposta em relação à componente $\sigma_{x}$.

Na Figura 5.9 existem concentrações de tensões consideráveis nos cantos superior e inferior direito devido à imposição das condições de vínculo nesses pontos (engaste), incompatíveis com a solução analítica na qual essas condições inexistem. Conseqüentemente, os elementos próximos ao engaste apresentarão índices de efetividade bem diferentes dos demais. Apesar desse inconveniente ainda nota-se que o EPMEFG é capaz de suavizar as concentrações de tensões.

Na Figura 5.10 fica mais visível o papel do EPMEFG. Nesse caso a resposta obtida com o MEFG não é tão precisa, porém baseado nessa resposta o novo estimador consegue determinar um campo de tensões bem próximo do campo calculado analiticamente excetuando-se a região do engaste pelas mesmas razões já comentadas e associadas às restrições de contorno. Levando-se em conta o Princípio de Saint-Venant os resultados para regiões do domínio não afetadas pelas restrições apresentam-se de ótima qualidade.

Na Figura 5.11 a situação é bem semelhante ao que acontece na Figura 5.8, porém chama-se a atenção que conforme esperado foi necessário utilizar um conjunto mais amplo de funções enriquecedoras, visto que a solução analítica envolve um polinômio mais complexo do que o caso da viga engastada.

Na Figura 5.12 mais uma vez é possível perceber uma significativa melhora na distribuição de $\sigma_{y}$ recuperado com o emprego do EPMEFG, particularmente porque a solução aproximada envolvida no MEFG não é capaz de reproduzir a variação cúbica de $\sigma_{y}$, na dimensão da altura da viga, prescrita pela solução exata. Esse problema poderia ser amenizado com recurso a um maior grau de enriquecimento no MEFG.

$\mathrm{Na}$ Figura 5.13 com certeza é onde o EPMEFG mostra seu melhor desempenho. Nessa figura, a solução originada com o MEFG indica diferenças significativas quando comparada a solução analítica. Por outro lado, a solução oriunda do EPMEFG praticamente coincide com a solução analítica. 


\section{CONSIDERAÇÕES FINAIS E CONCLUSÕES}

Este trabalho buscou oferecer uma contribuição ao estudo dos estimadores de erro a posteriori, baseados em recuperação do gradiente da solução, aplicados ao Método dos Elementos Finitos Generalizados. Para isso, foram apresentados inicialmente conceitos e definições matemáticas importantes relacionadas às estimativas de erro a posteriori, como também um breve levantamento sobre o atual estado da arte relacionado ao tema no âmbito do Método dos Elementos Finitos. A partir daquela revisão, procurou-se detalhar o emprego dos estimadores denominados Z e SPR, propostos por Zienkiewicz e Zhu, para gerar estimativas do erro. Posteriormente, destacou-se a incorporação proposta neste trabalho do procedimento SVD ao SPR para fornecer campos de tensões recuperadas, ainda no âmbito do MEF; essa incorporação passou a ser denominada SPR Modificado.

A próxima etapa do trabalho tratou de um estimador de erro para o MEFG. Devido a sua simplicidade conceitual, juntamente com a característica de explorar o conceito de aproximação por nuvens, concluíu-se que o SPR Modificado poderia vir a ser adaptado para o MEFG. Essa conclusão também foi influenciada pelos excelentes resultados alcançados com o SPR Modificado em diferentes ensaios para soluções obtidas com o MEF. Outro ponto positivo do SPR Modificado que contribuiu para sua extensão ao MEFG foi relativo à sua implementação computacional, visto que no contexto do MEF a mesma mostrou-se não muito complexa.

O SPR Modificado adaptado para o MEFG passou a ser intitulado EPMEFG. No EPMEFG, basicamente, a função polinomial local que permite recuperar os valores nodais suavizados de tensão tem por suporte a nuvem definida pelos elementos que dividem o nó em comum, e resulta da aplicação de um critério de aproximação por mínimos quadrados em relação aos pontos de superconvergência. O número desses pontos é definido considerando-se a restrição do campo de deslocamentos enriquecidos a cada elemento que compõe a nuvem. Finalmente, emprega-se a partição da unidade para a definição de valores recuperados de tensão em pontos do domínio cobertos por mais de uma nuvem, bem como para a obtenção de um estimador global a partir dos estimadores locais. 
Uma vez apresentados todos os estimadores estudados a etapa seguinte foi avaliar por meio de exemplos numéricos a eficiência dos estimadores Z, SPR Modificado e EPMEFG, o que exigiu o desenvolvimento de uma ferramenta computacional implementada em linguagem Fortran. A eficiência de cada um dos estimadores foi avaliada mediante a determinação dos índices de efetividade.

Com respeito aos exemplos relacionados ao MEF, do confronto dos índices de efetividade calculados para cada um dos estimadores, evidenciou-se que o SPR Modificado é mais eficiente do que o Estimador $Z$, principalmente nas malhas mais grosseiras de elementos triangulares. O melhor desempenho do SPR Modificado decorre, em princípio, do fato que o mesmo explora os pontos de superconvergência.

Ainda no contexto do MEF, demonstrou-se que ambos os estimadores discutidos são assintoticamente exatos, visto que na proporção em que a densidade da malha foi aumentada os índices de efetividade se aproximaram da unidade. Essa característica é essencial para que tais estimadores possam vir a ser empregados para guiar procedimentos adaptativos.

Por sua vez, o procedimento de recuperação dos gradientes da solução para o MEFG, introduzido neste trabalho e baseado nas idéias contidas no SPR Modificado, mostrou-se eficiente considerando-se os exemplos testados. Em virtude disso, torna-se razoável empregar a solução recuperada por esse procedimento em substituição à solução exata para fins de avaliar o erro de discretização. Em conseqüência, entende-se que o EPMEFG também possa vir a ser uma ferramenta útil para guiar procedimentos adaptativos no contexto do MEFG.

É importante destacar que o EPMEFG até o presente momento só foi testado com elementos quadrilaterais bilineares em malhas regulares. Assim sendo, para efetivamente viabilizar o emprego de um estimador de erro baseado no EPMEFG são necessários estudos complementares. Entre esses estudos destacam-se:

- O emprego de malhas distorcidas;

- A aplicação do procedimento para elementos de ordem superior e combinações de elementos;

- A utilização de enriquecimentos distintos para cada direção;

- A possibilidade de empregar o EPMEFG para problemas que envolvam singularidades. 


\section{REFERÊNCIAS BIBLIOGRÁFICAS}

AINSWORTH, M. e ODEN, J. T. (1997). A posteriori error estimation in finite element analysis. Computer Methods in Applied Mechanics and Engineering, v. 142, p. 1-88.

ALVES, M. M. (2010). Método da partição na análise de múltiplas fissuras. Tese (Doutorado). Escola de Engenharia de São Carlos, Universidade de São Paulo, São Carlos.

ARGÔLO, H. S. D. (2010). Emprego de formulações não-convencionais de elementos finitos na análise linear bidimensional de sólidos com múltiplas fissuras. Dissertação (Mestrado). Escola de Engenharia de São Carlos, Universidade de São Paulo, São Carlos.

BABUŠKA, I. e MELENK, J. M. (1997). The partition of unity finite element method. International Journal for Numerical Methods in Engineering, v. 40, p. 727-758.

BABUŠKA, I. e RHEINBOLDT, W. C. (1978). A posteriori error estimates for the finite element method. International Journal for Numerical Methods in Engineering, v. 12, p. 1597-1615.

BABUŠKA, I. e RHEINBOLDT, W. C. (1981). A posteriori error analysis of finite element solutions for one-dimensional problems. SIAM Journal on Numerical Analysis, v. 18, p. 565-589.

BABUŠKA, I., CALOZ, G. e OSBORN, J. E. (1994). Special finite element methods for a class of second order elliptic problems with rough coefficients. SIAM Journal on Numerical Analysis, v. 31, p. 745-981. 
BABUŠKA, I., STROUBOULIS, T., COPPS, K., GANGARAJ, S.K. e UPADHYAY, C.S. (1998). A posteriori error estimation for finite element and generalized finite element method. Technical Report 98-01, TICAM, University of Texas at Austin.

BANK, R. E. e WEISER, A. (1985). Some a posteriori error estimators for elliptic partial differential equations. Mathematics Computations, v. 44, p. 283-301.

BARBER, J. R. (2002). Elasticity. $2^{\text {nd }}$ Edition, Kluwer Academic Publishers.

BARLOW, J. (1976). Optimal stress locations in finite element models. International Journal for Numerical Methods in Engineering, v. 10, p. 243-251.

BARROS, F. B. (2002). Métodos sem malha e método dos elementos finitos generalizados em análise não-linear de estruturas. Tese (Doutorado). Escola de Engenharia de São Carlos, Universidade de São Paulo, São Carlos.

BARTELS, S. e CARSTENSEN, C. Each averaging technique yields reliable a posteriori error control in FEM on unstructured grids, Part II: Higher order FEM. Internet report - Christian-Albrechts-Universität. Janeiro de 2000. Disponível em: $<$ http://www.numerik.uni-kiel.de/reports/authors.html\#Carstensen/>. Acesso em: Fevereiro de 2011.

BLACKER, T. e BELYTSCHKO, T. (1994). Superconvergent patch recovery with equilibrium and conjoint interpolant enhancements. International Journal for Numerical Methods in Engineering, v. 37, p. 517-536.

CARSTENSEN, C. e FUNKEN, S. A. Averaging technique for FE-a posteriori error control in elasticity, Part I: Conforming FEM. Internet report - Christian-AlbrechtsUniversität. Fevereiro de 2000. Disponível em: <http://www.numerik.unikiel.de/reports/authors.html\#Carstensen/>. Acesso em: Fevereiro de 2011. 
DUARTE, C. A. (1991). Estudo da versão p do método dos elementos finitos para problemas de elasticidade e potencial. Dissertação (Mestrado), Departamento de Engenharia Mecânica da Universidade Federal de Santa Catarina.

DUARTE, C. A. (1996). The hp cloud method. Tese (Doutorado). University of Texas at Austin.

DUARTE, C. A. e ODEN, J. T. (1995). Hp clouds - a meshless method to solve boundary-value problems. Technical Report 95-05, TICAM, University of Texas at Austin.

DUARTE, C. A. e ODEN, J. T. (1996a). An $h p$ adaptive method using clouds. Computer Methods in Applied Mechanics and Engineering, v. 139, p. 237-262.

DUARTE, C. A. e ODEN, J. T. (1996b). Hp clouds - an $h p$ meshless method. Numerical Methods for Partial Differential Equations, v. 12, p. 673-705.

DUARTE, C. A., BABUŠKA, I. e ODEN, J. T. (2000). Generalized finite element methods for three-dimensional structural mechanics problems. Computer \& Structures, v. 77, p. 215-232.

EWING, R. E. (1990). A posteriori error estimation. Computer Methods in Applied Mechanics and Engineering, v. 82, p. 59-72.

GRÄTSCH, T. e BATHE, J. K. (2005). Review: A posteriori error estimation techniques in practical finite element analysis. Computer \& Structures, v. 83, p. 235265.

HINTON, E. e CAMPBELL, J. S. (1974). Local and global smoothing of discontinuous finite element functions using a least squares method. International Journal for Numerical Methods in Engineering, v. 8, p. 461-480. 
KELLY, D. W., GAGO, J. R., ZIENKIEWICZ, O. C. e BABUŠKA, I. (1983). A posteriori error analysis and adaptive processes in finite element method, Part 1: Error analysis. International Journal for Numerical Methods in Engineering, v. 19, p. 1593-1619.

KIM, D. -J., DUARTE, C. A. e PROENÇA, S. P. B (2009). Generalized finite element method with global-local enrichments for nonlinear fracture analysis. In: Second International Symposium on Solid Mechanics. Rio de Janeiro. Solid Mechanics in Brazil - Associação Brasileira de Engenharia e Ciências Mecânicas, v. 1, p. 317-330.

MANGINI, M. (2006). Método dos elementos finitos generalizados para análise de estruturas em casca de revolução. Dissertação (Mestrado). Escola de Engenharia de São Carlos, Universidade de São Paulo, São Carlos.

MELENK, J. M. e BABUŠKA, I. (1996). The partition of unity finite element method: basic theory and applications. Computer Methods in Applied Mechanics and Engineering, v. 139, p. 289-314.

ODEN, J. T., DUARTE, C. A. e ZIENKIEWICZ, O. C. (1998). A new cloud-based $h p$ finite element method. Computer Methods in Applied Mechanics and Engineering, v. 153 , p. $117-126$.

PACCOLA, R. R. e CODA, H. B. AcadView. Outubro de 2005. Disponível em: <http://www.set.eesc.usp.br/public/repositorio/acadview.php>. Acesso em: Janeiro de 2011.

PROENÇA, S. P. B. (2009). Introdução aos Métodos Numéricos - Notas de Aula. Escola de Engenharia de São Carlos, Universidade de São Paulo, São Carlos. 
PROENÇA, S. P. B. (2010). Singular Value Decomposition. Escola de Engenharia de São Carlos, Universidade de São Paulo, São Carlos.

QUARTERONI, A., SACCO, R., e SALERI, F. (2000). Numerical Mathematics, Springer.

STROUBOULIS, T., BABUŠKA, I. A. e COPPS, K. (2000). The design and analysis of the generalized finite element method. Computer Methods in Applied Mechanics and Engineering, v. 181, n. 1-3, p. 43-69.

STROUBOULIS, T., COPPS, K. e BABUŠKA, I. (2001). The generalized finite element method. Computer Methods in Applied Mechanics and Engineering, v. 190, p. 4081-4193.

TORRES, I. F. R. (2003). Desenvolvimento e aplicação do método dos elementos finitos generalizados em análise tridimensional não-linear de sólidos. Tese (Doutorado). Escola de Engenharia de São Carlos, Universidade de São Paulo, São Carlos.

WIBERG, N. E. e ABDULWAHAB, F. (1993). A posteriori error estimation based on superconvergent derivatives and equilibrium. International Journal for Numerical Methods in Engineering, v. 36, p. 2703-2724.

ZIENKIEWICZ, O. C. e TAYLOR, R. L. (1989). The Finite Element Method - vol.1: Basic Formulation and Linear Problems. $4^{\text {th }}$ Edition, McGraw-Hill.

ZIENKIEWICZ, O. C. e ZHU, J. Z. (1987). A simple error estimator and adaptive procedure for practical engineering analysis. International Journal for Numerical Methods in Engineering, v. 24, p. 337-357. 
ZIENKIEWICZ, O. C. e ZHU, J. Z. (1992a). The superconvergent patch recovery and a posteriori error estimates, Part 1: The recovery technique. International Journal for Numerical Methods in Engineering, v. 33, p. 1331-1364.

ZIENKIEWICZ, O. C. e ZHU, J. Z. (1992b). The superconvergent patch recovery and a posteriori error estimates, Part 2: Error estimates and adaptivity. International Journal for Numerical Methods in Engineering, v. 33, p. 1365-1382.

ZIENKIEWICZ, O. C., TAYLOR, R. L. e ZHU, J. Z. (2005). The Finite Element Method: Its Basis and Fundamentals. $6^{\text {th }}$ Edition, Elsevier Butterworth-Heinemann. 